Cochrane Database of Systematic Reviews

\title{
Interventions for treating traumatised permanent front teeth: avulsed (knocked out) and replanted (Review)
}

Day PF, Duggal M, Nazzal H

Day PF, Duggal M, Nazzal H.

Interventions for treating traumatised permanent front teeth: avulsed (knocked out) and replanted.

Cochrane Database of Systematic Reviews 2019, Issue 2. Art. No.: CD006542.

DOI: 10.1002/14651858.CD006542.pub3.

www.cochranelibrary.com 
TABLE OF CONTENTS

HEADER 1

ABSTRACT

PLAIN LANGUAGE SUMMARY

SUMMARY OF FINDINGS

BACKGROUND

OBJECTIVES

METHODS

Figure 1.

Figure 2.

RESULTS

Figure 3.

DISCUSSION

AUTHORS' CONCLUSIONS

ACKNOWLEDGEMENTS

REFERENCES

CHARACTERISTICS OF STUDIES

DATA AND ANALYSES

Analysis 1.1. Comparison 1 Hyperbaric oxygen versus control, Outcome 1 Periodontal healing at 12 months.

Analysis 1.2. Comparison 1 Hyperbaric oxygen versus control, Outcome 2 Tooth survival at 12 months.

Analysis 1.3. Comparison 1 Hyperbaric oxygen versus control, Outcome 3 Pulpal healing at 12 months.

Analysis 2.1. Comparison 2 Ledermix day 0-10 versus Ultracal day 7-10, Outcome 1 Peridontal healing at 12 months. ...........

Analysis 2.2. Comparison 2 Ledermix day 0-10 versus Ultracal day 7-10, Outcome 2 Tooth survival at 12 months. .................

Analysis 2.3. Comparison 2 Ledermix day 0-10 versus Ultracal day 7-10, Outcome 3 Discolouration (patient-reported) at 12 months - best case scenario for Ledermix.

Analysis 2.4. Comparison 2 Ledermix day 0-10 versus Ultracal day 7-10, Outcome 4 Discolouration (patient-reported) at 12 months - worst case scenario for Ledermix.

Analysis 3.1. Comparison 3 Pulp extirpation at day 0 (extra-oral) versus day 7 (intra-oral), Outcome 1 Radiographic resorption at 12 months.

Analysis 4.1. Comparison 4 Thymosin alpha 1 versus saline soaking prior to replantation, Outcome 1 Periodontal healing at 48 months.

Analysis 4.2. Comparison 4 Thymosin alpha 1 versus saline soaking prior to replantation, Outcome 2 Tooth survival at 12 months.

Analysis 4.3. Comparison 4 Thymosin alpha 1 versus saline soaking prior to replantation, Outcome 3 Tooth survival at 48 months.

APPENDICES

WHAT'S NEW

CONTRIBUTIONS OF AUTHORS

DECLARATIONS OF INTEREST

SOURCES OF SUPPORT

DIFFERENCES BETWEEN PROTOCOL AND REVIEW

INDEX TERMS 
[Intervention Review]

\section{Interventions for treating traumatised permanent front teeth: avulsed (knocked out) and replanted}

Peter F Day ${ }^{1}$, Monty Duggal², Hani Nazzal ${ }^{1}$

1Department of Paediatric Dentistry, Leeds Dental Institute, Leeds, UK. 2Department of Paediatric Dentistry, Faculty of Dentistry, National University of Singapore, Singapore, Singapore

Contact address: Peter F Day, Department of Paediatric Dentistry, Leeds Dental Institute, Clarendon Way, Leeds, LS2 9LU, UK. p.f.day@leeds.ac.uk.

Editorial group: Cochrane Oral Health Group.

Publication status and date: New search for studies and content updated (no change to conclusions), published in Issue 2, 2019.

Citation: Day PF, Duggal M, Nazzal H. Interventions for treating traumatised permanent front teeth: avulsed (knocked out) and replanted. Cochrane Database of Systematic Reviews 2019, Issue 2. Art. No.: CD006542. DOI: 10.1002/14651858.CD006542.pub3.

Copyright @ 2019 The Cochrane Collaboration. Published by John Wiley \& Sons, Ltd.

\section{A B S T R A C T}

\section{Background}

Traumatic dental injuries are common. One of the most severe injuries is when a permanent tooth is knocked completely out of the mouth (avulsed). In most circumstances the tooth should be replanted as quickly as possible. There is uncertainty on which interventions will maximise the survival and repair of the replanted tooth. This is an update of a Cochrane Review first published in 2010.

\section{Objectives}

To compare the effects of a range of interventions for managing traumatised permanent front teeth with avulsion injuries.

\section{Search methods}

Cochrane Oral Health's Information Specialist searched the following databases: Cochrane Oral Health's Trials Register (to 8 March 2018), Cochrane Central Register of Controlled Trials (CENTRAL; 2018, Issue 2) in the Cochrane Library (searched 8 March 2018), MEDLINE Ovid (1946 to 8 March 2018), and Embase Ovid (1980 to 8 March 2018). The US National Institutes of Health Ongoing Trials Registry (ClinicalTrials.gov) and the World Health Organization International Clinical Trials Registry Platform were searched for ongoing trials. No restrictions were placed on the language or date of publication when searching the electronic databases.

\section{Selection criteria}

We considered randomised and quasi-randomised controlled trials that included a minimum follow-up period of 12 months, for interventions for avulsed and replanted permanent front teeth.

\section{Data collection and analysis}

Two review authors independently selected studies, extracted data and assessed the risk of bias. Authors were contacted where further information about their study was required.

\section{Main results}

Four studies, involving a total of 183 participants and 257 teeth were identified. Each of the interventions aimed to reduce infection or alter the inflammatory response or both at the time of or shortly after the tooth or teeth were replanted. Each study assessed a different intervention and therefore it was not appropriate or possible to numerically synthesise the data. All evidence was rated as being of very low quality due to problems with risk of bias and imprecision of results. This means that we are very uncertain about all of the results presented in this review. 
One study at high risk of bias with 69 participants (138 teeth) compared a 20-minute soak with gentamycin sulphate for both groups prior to replantation with the experimental group receiving daily hyperbaric oxygen for 80 minutes for the first 10 days. There was some evidence of a benefit for the hyperbaric oxygen group in respect of periodontal healing, tooth survival, and pulpal healing.

One study at unclear risk of bias with 22 participants (27 teeth) compared the use of two root canal medicaments, Ledermix and Ultracal. There was insufficient evidence of a difference for periodontal healing or tooth survival. This was the only study to formally report adverse events with none identified. Study authors reported that Ledermix caused a greater level of patient dissatisfaction with the colour of avulsed and replanted teeth.

A third study at high risk of bias with 19 participants compared extra- or intra-oral endodontics for avulsed teeth which were stored dry for longer than 60 minutes before replantation. There was insufficient evidence of a difference in periodontal healing.

The fourth study at high risk of bias with 73 participants compared a 10-minute soak in either thymosin alpha 1 or saline before replantation followed by daily gingival injections with these same medicaments for the first 7 days. There was some evidence of a benefit for thymosin alpha 1 with respect to periodontal healing and tooth survival.

\section{Authors' conclusions}

Based on the results of the included studies, there is insufficient evidence to support or refute the effectiveness of different interventions for avulsed and replanted permanent front teeth. The overall quality of existing evidence was very low, and therefore great caution should be exercised when generalising the results of the included trials. There is urgent need for further well-designed randomised controlled trials.

\section{PLAIN LANGUAGE SUMMARY}

\section{Treatments for managing knocked out and replanted permanent front teeth}

\section{Review question}

The aim of this Cochrane Review was to find out which treatment for managing knocked out and replanted permanent front teeth was the most effective.

\section{Background}

Injuring your front teeth is common. One of the most severe injuries occurs when the tooth is knocked totally out of the mouth (avulsed). Often the best option is to replant the tooth as quickly as possible. This is true only for permanent teeth. Once replanted the tooth can heal in one of two ways if managed correctly. Ideally the ligaments around the root repair and the tooth can be expected to last as long as any other tooth, this is known as 'periodontal healing'. When there is too much damage to the ligaments, healing occurs by bony replacement. Over a number of years, the adjacent bony socket will remodel the tooth (replace the root with bone) leaving the tooth with no root. Once the root is replaced the visible part of the tooth, the crown, will eventually give way and be lost. This is called 'bony healing'. Bony healing causes significant problems in the medium term for children and treatments for this are the subject of a different Cochrane Review. A missing front tooth or teeth, as a result of not replanting an avulsed tooth, or as a result of bony healing over the medium to long term, can have a major effect on dental and facial 'good looks'. This can affect the individual's self-esteem and general social interaction, as well as how others think and see them.

\section{Study characteristics}

Authors from Cochrane Oral Health carried out this review and the evidence is up to date to 8 March 2018. The review investigated what treatments encourage the tooth to repair by periodontal healing. A total of four studies were included with a total of 183 participants with 257 teeth. One study involved children and young adults, with the other three involving children only. Each study evaluated a different treatment: hyperbaric oxygen, root canal pastes (Ledermix versus Ultracal), removal of the nerve of the tooth (pulp extirpation), and soaking the knocked out tooth in thymosin alpha 1 . Each of the interventions aimed to reduce infection or change the inflammatory response or both, at the time of or shortly after the tooth or teeth were replanted.

\section{Key results}

The evidence currently available is insufficient to draw reliable conclusions regarding the superiority of different interventions for knocked out and replanted permanent front teeth. There is urgent need for further well-designed randomised controlled trials.

\section{Quality of the evidence}

We judged the quality of the evidence to be very low due to problems with the design of the studies. 


\section{SUMMARY OF FINDINGS}

\section{Summary of findings for the main comparison. Hyperbaric oxygen compared with control for avulsed and replanted teeth}

Hyperbaric oxygen compared with control for avulsed and replanted teeth

Patient or population: people with avulsed and replanted permanent teeth

Setting: university dental clinic

Intervention: hyperbaric oxygen

Comparison: control

\begin{tabular}{|c|c|c|c|c|c|c|}
\hline \multirow[t]{2}{*}{ Outcomes } & \multicolumn{2}{|c|}{ Anticipated absolute effects } & \multirow{2}{*}{$\begin{array}{l}\text { Relative ef- } \\
\text { fect } \\
(95 \% \mathrm{CI})\end{array}$} & \multirow{2}{*}{$\begin{array}{l}\text { Number of } \\
\text { teeth/partici- } \\
\text { pants } \\
\text { (studies) }\end{array}$} & \multirow{2}{*}{$\begin{array}{l}\text { Quality of the } \\
\text { evidence } \\
\text { (GRADE) }\end{array}$} & \multirow[t]{2}{*}{ Comments } \\
\hline & Control risk & $\begin{array}{l}\text { Risk with in- } \\
\text { tervention } \\
(95 \% \mathrm{Cl})\end{array}$ & & & & \\
\hline $\begin{array}{l}\text { Periodontal } \\
\text { healing at } 12 \\
\text { months }\end{array}$ & $\begin{array}{l}431 \text { per } 1000 \\
\text { teeth }\end{array}$ & $\begin{array}{l}879 \text { per } 1000 \\
\text { teeth ( } 655 \text { to } \\
1000)\end{array}$ & $\begin{array}{l}\text { RR } 2.04 \text { (1.52 } \\
\text { to } 2.73 \text { ) }\end{array}$ & $\begin{array}{l}138 \text { teeth in } 69 \\
\text { patients } \\
(1 \mathrm{RCT})^{\star}\end{array}$ & $\begin{array}{l}\oplus \ominus \odot \ominus \\
\text { very low } 1\end{array}$ & $\begin{array}{l}\text { *Outcome reported at tooth rather than patient level } \\
\text { Estimate of RR was lower if patients lost to follow-up were in- } \\
\text { cluded in estimation assuming best possible outcome for con- } \\
\text { trol group } 1.87 \text { (1.42 to } 2.47)\end{array}$ \\
\hline $\begin{array}{l}\text { Tooth sur- } \\
\text { vival at } 12 \\
\text { months }\end{array}$ & $\begin{array}{l}815 \text { per } 1000 \\
\text { teeth }\end{array}$ & $\begin{array}{l}987 \text { per } 1000 \\
\text { teeth ( } 872 \text { to } \\
1000)\end{array}$ & $\begin{array}{l}\text { RR } 1.21 \text { (1.07 } \\
\text { to } 1.36)\end{array}$ & $\begin{array}{l}138 \text { teeth in } 69 \\
\text { patients } \\
(1 \mathrm{RCT})^{\star}\end{array}$ & $\begin{array}{l}\oplus \ominus \odot \odot \\
\text { very low } 1\end{array}$ & $\begin{array}{l}\text { *Outcome reported at tooth rather than patient level } \\
\text { Estimate of RR was lower if patients lost to follow-up were in- } \\
\text { cluded in estimation assuming best possible outcome for con- } \\
\text { trol group } 1.17 \text { (1.03 to } 1.31 \text { ) }\end{array}$ \\
\hline $\begin{array}{l}\text { Pulpal heal- } \\
\text { ing at } 12 \\
\text { months }\end{array}$ & $\begin{array}{l}723 \text { per } 1000 \\
\text { teeth }\end{array}$ & $\begin{array}{l}904 \text { per } 1000 \\
\text { teeth ( } 766 \text { to } \\
1000)\end{array}$ & $\begin{array}{l}\text { RR } 1.25 \text { (1.06 } \\
\text { to } 1.48)\end{array}$ & $\begin{array}{l}138 \text { teeth in } 69 \\
\text { patients } \\
(1 \mathrm{RCT})^{\star}\end{array}$ & $\begin{array}{l}\oplus \ominus \ominus \ominus \\
\text { very low } 1\end{array}$ & $\begin{array}{l}\text { *Outcome reported at tooth rather than patient level } \\
\text { Estimate of RR was lower if patients lost to follow-up were in- } \\
\text { cluded in estimation assuming best possible outcome for con- } \\
\text { trol group } 1.20 \text { (1.01 to } 1.41)\end{array}$ \\
\hline
\end{tabular}

No other outcomes reported

Cl: confidence interval; $\mathbf{R C T}$ : randomised controlled trial; RR: risk ratio.

\section{GRADE Working Group grades of evidence}

High quality: further research is very unlikely to change our confidence in the estimate of effect.

Moderate quality: further research is likely to have an important impact on our confidence in the estimate of effect and may change the estimate.

Low quality: further research is very likely to have an important impact on our confidence in the estimate of effect and is likely to change the estimate. 


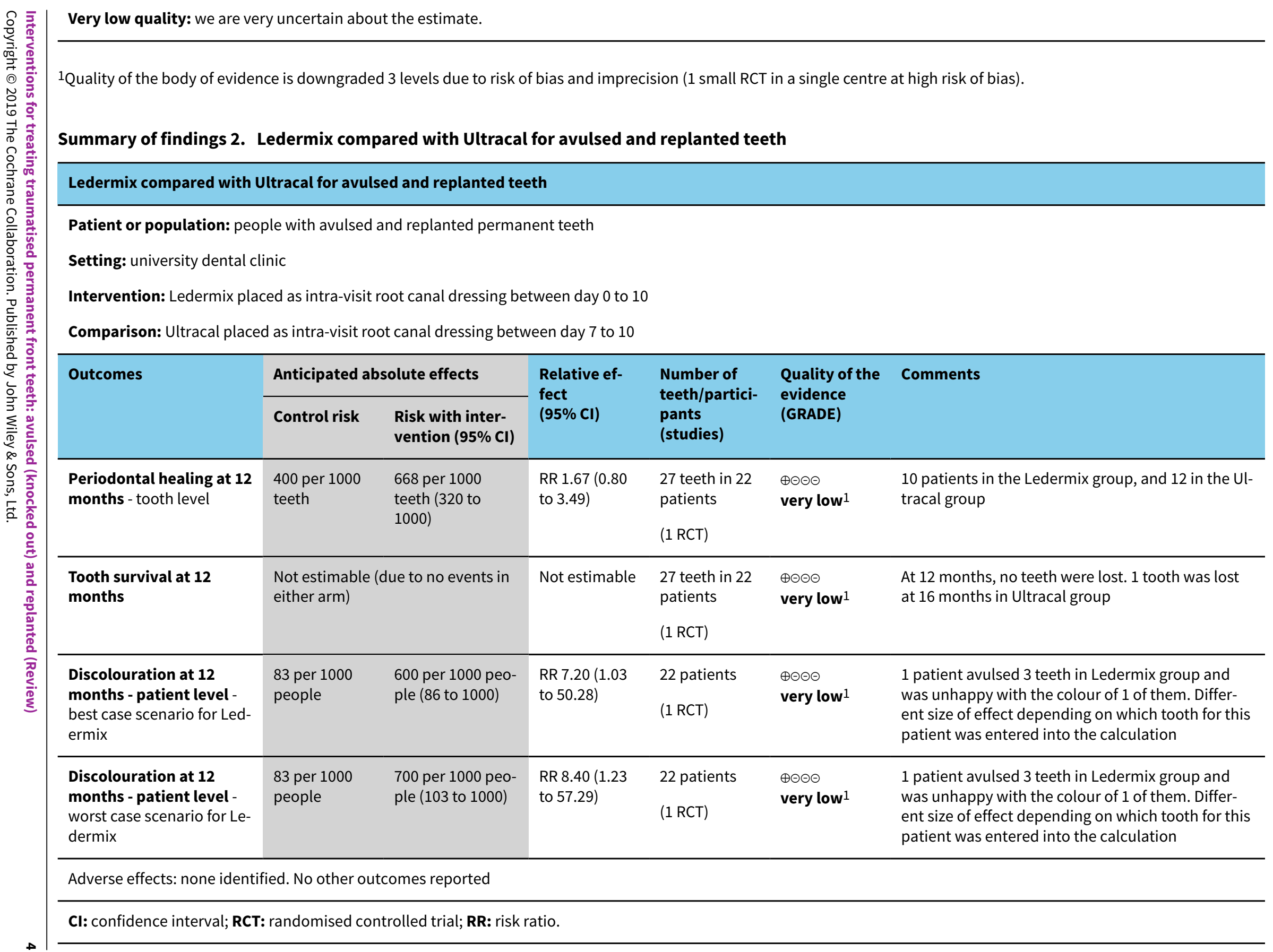


GRADE Working Group grades of evidence

High quality: further research is very unlikely to change our confidence in the estimate of effect.

Moderate quality: further research is likely to have an important impact on our confidence in the estimate of effect and may change the estimate.

Low quality: further research is very likely to have an important impact on our confidence in the estimate of effect and is likely to change the estimate.

Very low quality: we are very uncertain about the estimate.

${ }^{1}$ Quality of the body of evidence is downgraded 3 levels due to risk of bias and imprecision ( 1 small RCT at unclear risk of bias in a single setting that failed to recruit sufficient participants to meet power calculation for primary outcome - periodontal healing).

\section{Summary of findings 3 . Extra-oral pulp extirpation at day 0 compared with intra-oral extirpation at day 7 for avulsed and replanted teeth}

\section{Extra-oral pulp extirpation at day 0 compared with intra-oral extirpation at day 7 for avulsed and replanted teeth}

Patient or population: people with avulsed and replanted permanent teeth

Setting: university dental clinic

Intervention: extra-oral extirpation at day 0

Comparison: intra-oral extirpation at day 7

\begin{tabular}{|c|c|c|c|c|c|c|}
\hline \multirow[t]{2}{*}{ Outcomes } & \multicolumn{2}{|c|}{ Anticipated absolute effects } & \multirow{2}{*}{$\begin{array}{l}\text { Relative effect } \\
(95 \% \mathrm{Cl})\end{array}$} & \multirow{2}{*}{$\begin{array}{l}\text { Number of } \\
\text { participants } \\
\text { (studies) }\end{array}$} & \multirow{2}{*}{$\begin{array}{l}\text { Quality of the } \\
\text { evidence } \\
\text { (GRADE) }\end{array}$} & \multirow[t]{2}{*}{ Comments } \\
\hline & Control risk & $\begin{array}{l}\text { Risk with intervention } \\
(95 \% \mathrm{CI})\end{array}$ & & & & \\
\hline $\begin{array}{l}\text { Radiographic resorption (a } \\
\text { proxy measure for periodon- } \\
\text { tal healing) at } 12 \text { months }\end{array}$ & $\begin{array}{l}333 \text { per } 1000 \\
\text { people }\end{array}$ & $\begin{array}{l}450 \text { per } 1000 \text { people ( } 270 \text { to } \\
747 \text { ) }\end{array}$ & $\begin{array}{l}\text { RR } 1.35 \text { (0.81 to } \\
2.24)\end{array}$ & $\begin{array}{l}19 \\
(1 \mathrm{RCT})^{*}\end{array}$ & $\begin{array}{l}\oplus \ominus \ominus \ominus \\
\text { very low } 1\end{array}$ & $\begin{array}{l}{ }^{*} \text { For all participants the ex- } \\
\text { tra-oral dry time was greater } \\
\text { than } 60 \text { minutes }\end{array}$ \\
\hline
\end{tabular}

No other outcomes reported

Cl: confidence interval; $\mathbf{R C T}$ : randomised controlled trial; RR: risk ratio.

\section{GRADE Working Group grades of evidence}

High quality: further research is very unlikely to change our confidence in the estimate of effect.

Moderate quality: further research is likely to have an important impact on our confidence in the estimate of effect and may change the estimate.

Low quality: further research is very likely to have an important impact on our confidence in the estimate of effect and is likely to change the estimate.

Very low quality: we are very uncertain about the estimate.

${ }^{1}$ Quality of the body of evidence is downgraded 3 levels due to risk of bias and imprecision (1 small RCT in a single centre at high risk of bias) 


\begin{tabular}{|c|c|c|c|c|c|c|}
\hline \multicolumn{7}{|c|}{ Thymosin alpha 1 compared with control for avulsed and replanted teeth } \\
\hline $\begin{array}{l}\text { Patient or pop } \\
\text { Setting: univer } \\
\text { Intervention: } \\
\text { Comparison: }\end{array}$ & $\begin{array}{l}\text { lation: people } \\
\text { ity dental clinic } \\
\text { ymosin alpha } \\
\text { ntrol (saline) }\end{array}$ & th avulsed and $r$ & anted permane & : teeth & & \\
\hline \multirow[t]{2}{*}{ Outcomes } & \multicolumn{2}{|c|}{ Anticipated absolute effects } & \multirow{2}{*}{$\begin{array}{l}\text { Relative ef- } \\
\text { fect } \\
(95 \% \mathrm{Cl})\end{array}$} & \multirow{2}{*}{$\begin{array}{l}\text { Number of } \\
\text { participants } \\
\text { (studies) }\end{array}$} & \multirow{2}{*}{$\begin{array}{l}\text { Quality of the } \\
\text { evidence } \\
\text { (GRADE) }\end{array}$} & \multirow[t]{2}{*}{ Comments } \\
\hline & Control risk & $\begin{array}{l}\text { Risk with in- } \\
\text { tervention } \\
(95 \% \mathrm{Cl})\end{array}$ & & & & \\
\hline $\begin{array}{l}\text { Periodontal } \\
\text { healing at } 48 \\
\text { months }\end{array}$ & $\begin{array}{l}138 \text { per } 1000 \\
\text { people }\end{array}$ & $\begin{array}{l}772 \text { per } 1000 \\
\text { people (306 to } \\
1000)\end{array}$ & $\begin{array}{l}\text { RR } 5.60(2.22 \\
\text { to } 14.11)\end{array}$ & $\begin{array}{l}73 \\
(1 \mathrm{RCT})\end{array}$ & $\begin{array}{l}\oplus \ominus \ominus \ominus \\
\text { very low } 1\end{array}$ & $\begin{array}{l}\text { An imbalance was seen in loss to follow-up between the } 2 \\
\text { groups. If those lost to follow-up in the control group were in- } \\
\text { cluded in estimation assuming best possible outcome for control } \\
\text { group RR for this outcome is } 1.70 \text { ( } 1.18 \text { to } 2.45)\end{array}$ \\
\hline $\begin{array}{l}\text { Tooth sur- } \\
\text { vival at } 12 \\
\text { months }\end{array}$ & $\begin{array}{l}655 \text { per } 1000 \\
\text { people }\end{array}$ & $\begin{array}{l}957 \text { per } 1000 \\
\text { people }(727 \text { to } \\
1000)\end{array}$ & $\begin{array}{l}\text { RR } 1.46(1.11 \\
\text { to } 1.91)\end{array}$ & $\begin{array}{l}73 \\
(1 \mathrm{RCT})\end{array}$ & $\begin{array}{l}\oplus \ominus \ominus \ominus \\
\text { very low } 1\end{array}$ & $\begin{array}{l}\text { An imbalance was seen in loss to follow-up between the } 2 \\
\text { groups. If those lost to follow-up in the control group were in- } \\
\text { cluded in estimation assuming best possible outcome for control } \\
\text { group RR for this outcome is } 1.20 \text { ( } 1.01 \text { to } 1.43 \text { ) }\end{array}$ \\
\hline $\begin{array}{l}\text { Tooth sur- } \\
\text { vival at } 48 \\
\text { months }\end{array}$ & $\begin{array}{l}241 \text { per } 1000 \\
\text { people }\end{array}$ & $\begin{array}{l}864 \text { per } 1000 \\
\text { people (449 to } \\
1000)\end{array}$ & $\begin{array}{l}\text { RR } 3.58(1.86 \\
\text { to } 6.89)\end{array}$ & $\begin{array}{l}73 \\
(1 \mathrm{RCT})\end{array}$ & $\begin{array}{l}\oplus \odot \odot \odot \\
\text { very low } 1\end{array}$ & $\begin{array}{l}\text { An imbalance was seen in loss to follow-up between the } 2 \\
\text { groups. If those lost to follow-up in the control group were in- } \\
\text { cluded in estimation assuming best possible outcome for control } \\
\text { group RR for this outcome is } 1.65 \text { ( } 1.21 \text { to } 2.26 \text { ) }\end{array}$ \\
\hline \multicolumn{7}{|c|}{ A benefit in pain scores reported on day 1 for thymosin alpha 1 group but no difference found days 2 and 5 . No other outcomes reported } \\
\hline \multicolumn{7}{|c|}{ Cl: confidence interval; $\mathbf{R C T}$ : randomised controlled trial; RR: risk ratio. } \\
\hline \multicolumn{7}{|c|}{$\begin{array}{l}\text { GRADE Working Group grades of evidence } \\
\text { High quality: further research is very unlikely to change our confidence in the estimate of effect. } \\
\text { Moderate quality: further research is likely to have an important impact on our confidence in the estimate of effect and may change the estimate. } \\
\text { Low quality: further research is very likely to have an important impact on our confidence in the estimate of effect and is likely to change the estimate. } \\
\text { Very low quality: we are very uncertain about the estimate. }\end{array}$} \\
\hline
\end{tabular}

${ }^{1}$ Quality of the body of evidence is downgraded 3 levels due to risk of bias and imprecision (1 small RCT in a single centre at high risk of bias). 


\section{B A C K G R O U N D}

\section{Description of the condition}

Traumatic dental injuries (TDIs) are common, with between $6 \%$ to $34 \%$ of children aged 8 to 15 years old experiencing damage to their permanent teeth (Chadwick 2006; Hamilton 1997; Pitts 2015). One of the most severe dento-alveolar injuries is avulsion, where the tooth or teeth are completely knocked out of the mouth. This injury accounts for between $0.5 \%$ to $3 \%$ of dento-alveolar trauma to permanent teeth (Andreasen 2007). A study analysing a large trauma database in Denmark, has demonstrated that the incidence of avulsion injuries increases with age (Lauridsen 2012). In the worst scenarios the tooth or teeth are lost or extracted due to the failure of the replanted tooth. A UK national survey (Pitts 2015) reported a prevalence of $0.4 \%$ of 12 -year old children with missing anterior teeth as a result of trauma. Over three quarters of all traumatic oral injuries occur in childhood and in this age group, the mouth was the fourth most frequent site to injure, despite occupying only $1 \%$ of body surface (Eilert-Petersson 1997).

Accidental falls, sporting injuries, cycling accidents, and assault have been identified as common causes for TDIs in childhood (Gulinelli 2008; Wright 2007). TDIs most frequently affect a single tooth, but certain trauma events, such as sport, violence and traffic accidents can result in injuries to multiple teeth (Glendor 2008). Upper anterior teeth are most at risk for traumatic dental injuries. $90 \%$ of teeth injured are the anterior teeth, of which $79 \%$ are upper central incisors (Jacobsen and Andreasen 2001). There are a number of risk factors associated with the incidence of dental trauma. Boys experience dental injuries at least twice as often as girls (Glendor 2008). Physical characteristics such as increased overjet and incomplete lip closure have long been identified as significant risk factors for dental trauma (Burden 1995; Kania 1996; Pitts 2015).

In most circumstances the avulsed permanent tooth or teeth should be replanted as quickly as possible (BSPD 2012; IADT 2012). Where parents, bystanders or healthcare professionals do not feel confident to replant the tooth, the tooth should be placed in a storage medium such as milk and the patient should access dental care as an emergency e.g. as quickly as possible, ideally within the first 90 minutes (BSPD 2012; IADT 2012). The sooner the tooth is replanted the better the prognosis.

\section{Description of the intervention}

Treatment can be divided into the time frame in which it is undertaken e.g. emergency, short, medium and long term. The most important determinant of success is the emergency care.

Emergency care: this is the treatment that is provided in the short period after the injury. In the most basic form it includes how the tooth was stored prior to replantation, replantation and splinting. In this time period treatment may include systemic or topical treatment or both to minimise infection and alter the inflammatory response (such as antibiotics, disinfection of the root surface, root canal or socket).

Short-term care: this includes treatment undertaken in the time period between the emergency visit to 3 months after the injury. In this time period the periodontal ligament and cementum will heal. Treatment may include systemic or topical treatment or both to minimise infection (such as disinfection of the root canal, or use of an antimicrobial mouthwash), or alter the inflammatory response (such as medicaments placed in the root canal) or both. Other treatments will include pain and symptom management as well as splint removal.

Treatment can also be provided in the medium- ( 3 to 12 months) and long-term (greater than 12 months) time frame. Often care over this time point will consist of managing the consequences of how the tooth has healed especially in the childhood and adolescent population (Day 2008) or correcting aesthetic concerns of the patient.

Tooth avulsion is one of the most severe traumatic dental injuries requiring multiple appointments (Keasberry 2013), interdisciplinary management (Day 2008), and long-term management involving advanced surgical interventions (Day 2008). These usually incur high direct costs (averaging CAD 1780 in the first year alone (Nguyen 2004)) and indirect costs to the child and family (Glendor 2001).

\section{How the intervention might work}

The damage to the periodontal ligament and adjacent cementum (PDL) at the time of injury, the conditions of a tooth's subsequent storage and the duration prior to replantation all profoundly influence the prognosis (Andreasen 1995; Barrett 1997; Kinirons 2000). The PDL cells very quickly desiccate if left in dry conditions. Consequently the gold standard for such an injury is to replant the tooth as quickly as possible. Where the tooth is not replanted at the scene of the accident, storage of the tooth in a medium to preserve the vitality of the PDL is essential. Once replanted the avulsed tooth will need to be splinted, e.g. supported by the adjacent teeth, until healing is sufficient for the tooth to maintain its own position during eating, speaking and other physiological functions.

PDL healing is the primary outcome measure when assessing interventions for tooth avulsion. Clinical interventions are aimed at promoting favourable healing of the PDL. These can include reducing infection or modifying the inflammatory response or both, since both infection and inflammatory response can reduce the chances of PDL healing. Long-term survival of the tooth only occurs where favourable PDL healing has occurred. In this situation the tooth can be expected to survive as long as any other tooth.

Where the healing of the PDL is unfavourable, replacement root resorption of the tooth takes place. This happens where due to the lack of a viable PDL there is no longer any protection of the root from the surrounding bone (in the socket). The bone, like all bones, undergoes continual physiological remodelling (resorption and replacement). The root is gradually replaced by bone and depending on age this process can take between 2 and 20 years (Andersson 1989; Barrett 1997). Eventually with no root left, the crown of the tooth fractures, leaving the patient with a missing front tooth. In some clinical situations due to a prolonged extraoral time or extended dry time prior to replantation, PDL healing will be unfavourable. Interventions in this scenario aim to minimise infection or modify the inflammatory response or both to slow the resorption process down thereby prolonging the survival of the tooth.

Where replacement resorption occurs there is a failure of further dento-alveolar bone growth. This has few consequences in an adult patient who has completed their facial growth. However, in 
children there is still significant alveolar growth especially in the vertical component (Malmgren 2002). As a result, the surrounding teeth undergo continued vertical bony growth while the ankylosed tooth (where replacement resorption has occurred) fuses to the bone in the position it was replanted and fails to erupt further. This can result in significant complications in aesthetics and is most appropriately managed by an interdisciplinary team (BSPD 2012; Day 2008). Despite these potential longer term complications, however, in the emergency situation replanting the tooth is almost always the most appropriate treatment option. Ultimately this is a reversible decision. Even if unfavourable healing occurs, the replanted tooth will act as a space and bone maintainer and provides excellent aesthetics. This will provide a shortterm solution and allows time for treatment planning and the development of a comprehensive treatment plan (Day 2008; de Souza 2015).

\section{Why it is important to do this review}

Despite the treatment provided, this injury carries one of the poorest outcomes for dento-alveolar trauma with $73 \%$ to $96 \%$ of replanted teeth eventually being lost (Andreasen 2007). Nguyen and colleagues reported that the mean treatment time per individual, following replantation of a permanent incisor, was estimated to be 7.2 hours in the first year alone (Nguyen 2004). The authors advised that this was a conservative estimate, as it did not include time for radiographs, interdisciplinary assessment visits or denture fabrication, if required. There were approximately 1.2 emergency examinations and 4.8 reassessment examinations per individual. $90 \%$ of patients and $86 \%$ of parents reported loss of school and work time (Nguyen 2004).

Glendor and colleagues in Scandinavia reported that on average there were 11.9 visits in the first year following severe dental trauma and that 1.7 hours were spent on the emergency visit and 6.9 hours spent on follow-up planned visits. These estimates of time did not include travel time for the patient to and from the clinic, it was in fact estimated that direct dental chair time made up only $16 \%$ of the time taken by parents and children to attend these appointments (Glendor 2001). A UK study reported that following a TDI the median number of visits to a specialist centre for the required treatment was 9 , with a range of 1 to 28 visits. The authors acknowledged that specialist centres in the UK rarely provide acute care for TDI and therefore this may be an underestimation of the total number of visits required to manage TDI. They identified that $76 \%$ of children completed their treatment within 4 years - which implies that $24 \%$ were still attending for treatment over 4 years after the initial injury (Keasberry 2013).

An estimation of treatment costs is challenging and may only be approximated; this is complicated by the fact that most injuries occur in childhood, while definitive rehabilitation costs frequently continue into adulthood (Lee and Divaris 2009). Costs estimates for providing treatment for TDI over the short and medium term vary from GBP 600 to GBP 1200 (Borum and Andreasen 2001; Jacobsen and Andreasen 2001; Keasberry 2013; Nguyen 2004; Wong and Kolokotsa 2004).

Missing a front tooth is a particularly undesirable outcome especially in childhood and adolescence. It can have a major effect on dental and facial aesthetics due to the prominence of the maxillary teeth. Visibly missing anterior teeth were considered to be the most facially and dentally unattractive feature in one
American study (Royal College of Surgeons 1997). This can affect the individual's self-esteem and general social interaction. It will also affect the perceptions of the child or adolescent made by peers and adults (Marcenes and Ryda 2007; Rodd 2010; Vlok 2011) and influence children's oral health-related quality of life (Berger 2009; Cortes 2002; Fakhruddin 2008; Porritt 2011). Children and adolescents who sustain a dental injury severe enough to warrant splinting of the maxillary anterior teeth suffer an immediate decrease in their quality of life with the impact still present a year after the initial injury (Berger 2009). At least two studies assessing the impact of severe dental trauma on the quality of life of children found that scores obtained on the Child Perception Questionnaire approximated to values reported in children with cleft lip and palate, and exceeded values for children with dental caries or undergoing orthodontic treatment (Berger 2009; Rodd 2011).

Consequently treatment interventions that can facilitate PDL healing and therefore long-term tooth survival are of fundamental importance. This Cochrane Reviews seeks to identify high-quality evidence for managing traumatised permanent teeth with avulsion injuries. This version is an update of the Cochrane Review first published in 2010 (Day 2010).

\section{O B JECT IVES}

To compare the effects of a range of interventions for managing traumatised permanent front teeth with avulsion injuries.

\section{METHODS}

\section{Criteria for considering studies for this review Types of studies}

We considered randomised and quasi-randomised controlled trials (RCTs) that included a minimum follow-up period of 12 months.

\section{Types of participants}

Patients who attended a dental clinic (for diagnosis, treatment or observation) with tooth avulsion involving one or more permanent front teeth. This included patients who may have received this initial management (replanting the tooth back in the socket) from other healthcare professionals such as general medical practitioners, accident and emergency departments, or a member of the public or family.

We excluded patients if:

- a primary tooth was avulsed;

- a patient presented with a specific medical history that could affect their dental management, e.g. immuno-compromised patient where replantation may interfere with their general health and therefore such treatment may be contraindicated;

- the follow-up period was less than 12 months.

\section{Types of interventions}

We considered the following interventions.

- Treatment with antibiotics. This could include comparisons with no antibiotics, placebo or between different types of antibiotics.

- The timing of pulp extirpation, for example immediate (either extra-oral prior to replantation or intra-oral once the tooth was replanted), delayed or no extirpation. 
- The type of root canal medicaments used. This could include comparisons with no medicament, placebo or different types of medicaments.

- The replantation procedures, for example comparisons with different techniques and protocols for replanting the tooth. This intervention would include how the tooth was handled prior to replantation.

- The storage of the tooth prior to replantation. This could include comparisons of different storage mediums, duration in each or dry storage.

- Fixation and stabilisation procedures. These could include comparisons with different types of splints, no splint or the duration of the splinting period.

- The care following tooth replantation. This could include comparisons with the use of mouthwashes, oral care regimens, or other medical or surgical interventions or both. It was expected that these would be used during the first 2 months after replantation as this is the healing period for the periodontal ligament.

\section{Types of outcome measures}

\section{Primary outcomes}

- Periodontal ligament healing (may include proxy outcomes such as extent of radiographic root resorption).

\section{Secondary outcomes}

- Tooth survival.

- Pulpal healing.

- Pain.

- Aesthetics (discolouration).

- Oral health-related quality of life.

- Trauma-related dental anxiety.

- Infraocclusion.

- Cost: financial, clinic cost, dentist time, number of visits, time in dental chair, patient's time off work/school.

- Other complications or adverse effects.

\section{Search methods for identification of studies}

\section{Electronic searches}

Cochrane Oral Health's Information Specialist conducted systematic searches in the following databases for randomised/ quasi-randomised controlled trials and controlled clinical trials. There were no language, publication year or publication status restrictions:

- Cochrane Oral Health's Trials Register (searched 8 March 2018) (Appendix 1);

- Cochrane Central Register of Controlled Trials (CENTRAL; 2018, Issue 2) in the Cochrane Library (searched 8 March 2018) (Appendix 2);

- MEDLINE Ovid (1946 to 8 March 2018) (Appendix 3);

- Embase Ovid (1980 to 8 March 2018) (Appendix 4).

Subject strategies were modelled on the search strategy designed for MEDLINE Ovid. Where appropriate, they were combined with subject strategy adaptations of the highly sensitive search strategy designed by Cochrane for identifying randomised/quasi- randomised controlled trials and controlled clinical trials as described in the Cochrane Handbook for Systematic Reviews of Interventions Chapter 6 (Lefebvre 2011).

\section{Searching other resources}

The following trial registries were searched for ongoing studies:

- US National Institutes of Health Ongoing Trials Register ClinicalTrials.gov (clinicaltrials.gov; searched 8 March 2018) (Appendix 5);

- World Health Organization International Clinical Trials Registry Platform (apps.who.int/trialsearch; searched 8 March 2018) (Appendix 6).

We searched the reference lists of included studies and relevant systematic reviews for further studies.

We did not perform a separate search for adverse effects of interventions used, we considered adverse effects described in included studies only.

\section{Data collection and analysis}

\section{Selection of studies}

Those studies identified by the searches were reviewed by two authors (Peter Day (PD) and Monty Duggal (MD)) in the original review and by PD and Hani Nazzal (HN) in this updated version. Independently each review author assessed the title and abstract for their relevance to the subject area and whether it appeared to be an RCT involving treatment interventions for avulsed and replanted teeth. The search was designed to be sensitive and include controlled clinical trials, these were filtered out early in the selection process if they were not randomised. A full copy of all potentially relevant studies and those where there were insufficient data to make a decision were obtained. Each review author reviewed the full-text papers independently and any disagreement was resolved by discussion. Since PD and MD were also authors of Day 2012, Philip Riley (PR) from Cochrane Oral Health and $\mathrm{HN}$ assessed this trial independently and made a decision on its inclusion.

\section{Data extraction and management}

For studies where there was difficulty in clarifying certain details of the methodology, email correspondence was undertaken (PD) to ensure that the study details were correctly interpreted. In some cases this then resulted in the exclusion of the study and these were then listed in the 'Characteristics of excluded studies' table.

For studies fulfilling the inclusion criteria, PD and MD extracted data using an adapted data collection form from a previous Cochrane Review (Al Ansary 2009) which was later withdrawn from the Cochrane Library. For this updated review, a specially designed data extraction form, according to the checklist table 7.3.a of the Cochrane Handbook for Systematic Reviews of Interventions (Higgins 2011), was used by HN and PR. We reported the information extracted in the 'Characteristics of included studies' table. Where there was any confusion or uncertainty, further discussions occurred with PD or in the original review with MD.

We recorded the following data for each included trial.

- The year of publication and country of origin. 
- Sample size, age of participants and dropouts/withdrawals.

- Study participants and outcomes.

- Detailed description of interventions, techniques and materials used.

- Prognostic factors related to the injury and length and type of storage prior to replantation.

- Duration of follow-up.

- Information on adverse events or effects.

\section{Assessment of risk of bias in included studies}

Two review authors independently assessed the risk of bias of each included study using the Cochrane domain-based, two-part tool as described in Chapter 8 of the Cochrane Handbook for Systematic Reviews of Interventions 5.1.0 (Higgins 2011). We carried out the assessment without blinding the name of trial authors, institutions, and journals. $\mathrm{HN}$ and PR independently assessed the risk of bias in Day 2012.

We investigated the following domains:

- sequence generation;

- allocation concealment;

- blinding of participants and personnel;
- blinding of outcome assessors;

- incomplete outcome data addressed;

- selective outcome reporting; and

- other sources of bias.

We completed a 'Risk of bias' table for each study. Judgements were made for each domain using the following categories: low risk of bias, high risk of bias, or unclear risk of bias.

We categorised the overall risk of bias of individual studies. Studies were categorised as being at low, high, or unclear risk of bias according to the following criteria:

- low risk of bias (plausible bias unlikely to seriously alter the results) if all domains were at low risk of bias;

- high risk of bias (plausible bias that seriously weakens confidence in the results) if one or more domains were at high risk of bias; or

- unclear risk of bias (plausible bias that raises some doubt about the results) if one or more domains were at unclear risk of bias.

We also presented the risk of bias results graphically by domain for each study together with an overall risk of bias (Figure 1; Figure 2).

Figure 1. Risk of bias graph: review authors' judgements about each risk of bias item presented as percentages across all included studies.

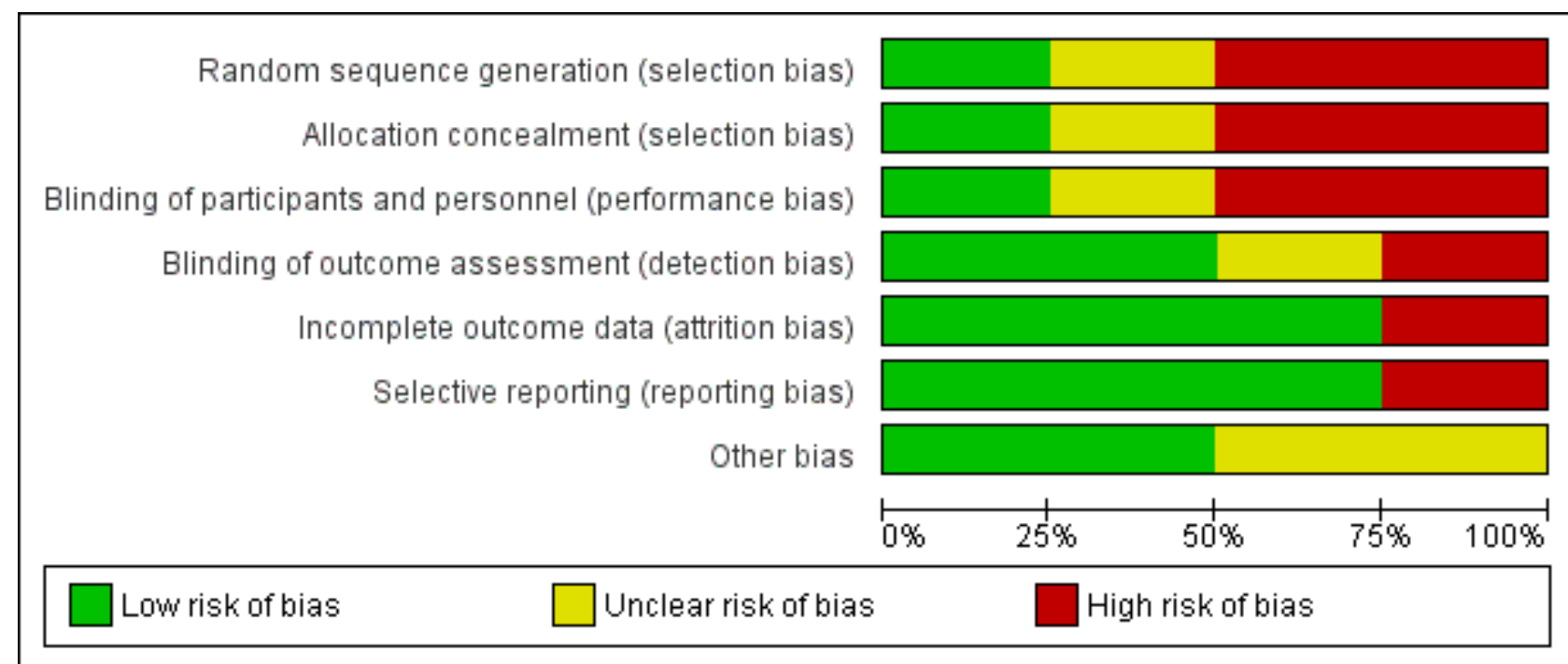


Figure 2. Risk of bias summary: review authors' judgements about each risk of bias item for each included study.

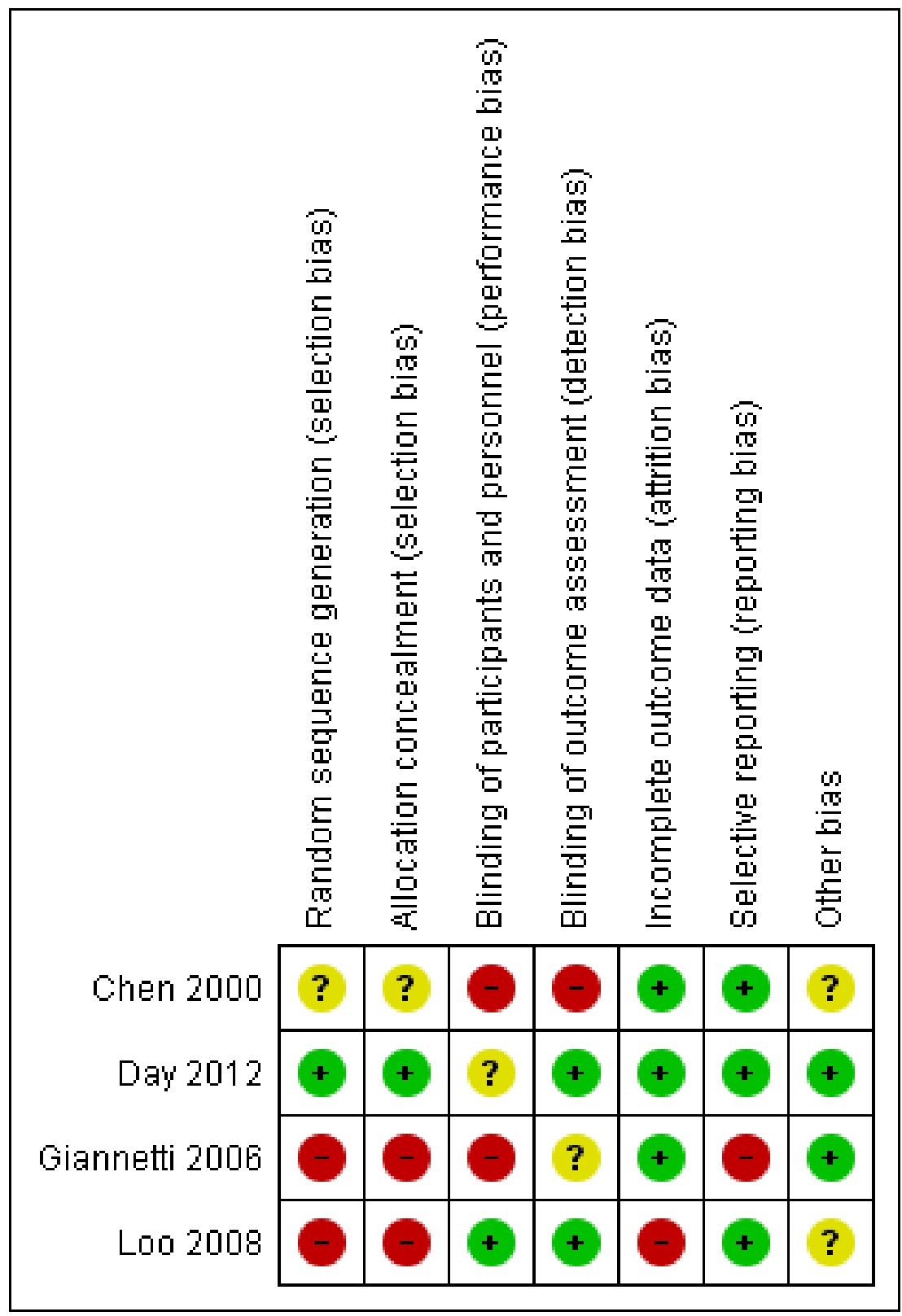

\section{Measures of treatment effect}

We analysed included studies according to the criteria described in Chapter 9 of the Cochrane Handbook for Systematic Reviews of Interventions Version 5.1.0 (Higgins 2011). For dichotomous data, risk ratio was applied and for continuous data the mean difference or standardized mean difference was used when different methods for measuring effects were used. Estimate of effect was presented with $95 \%$ confidence intervals.

\section{Unit of analysis issues}

Participants were the preferred unit of analysis. Where participants have multiple teeth injured then full reporting of the outcomes for each tooth was expected. An email correspondence with study authors was undertaken if such information was not initially available. Only where multilevel modelling, or appropriate analysis had been undertaken to identify the effect of the intervention at both patient and tooth level, could the data be fully used in any meta-analysis.

\section{Dealing with missing data}

We contacted study authors to clarify missing data or data which were not clearly reported. With this information intention-to-treat (ITT) analysis was undertaken for patients lost to follow-up in each study and the results reported if they came close to changing the level of confidence in the risk ratio.

\section{Assessment of heterogeneity}

In future updates, if a number of studies report similar outcome measures, statistical heterogeneity will be assessed by inspection of the point estimates and confidence intervals on the forest plots. 
The variation in treatment effects will be assessed by means of Cochran's test for heterogeneity and quantified by the $\mathrm{I}^{2}$ statistic. Heterogeneity will be considered statistically significant if $P$ value is $<0.10$. A rough guide to the interpretation of $\mathrm{I}^{2}$ given in the Cochrane Handbook for Systematic Reviews of Interventions is $0 \%$ to $40 \%$ might not be important, $30 \%$ to $60 \%$ may represent moderate heterogeneity, $50 \%$ to $90 \%$ may represent substantial heterogeneity, and $75 \%$ to $100 \%$ considerable heterogeneity (Higgins 2011).

\section{Assessment of reporting biases}

In future updates if sufficient number of studies (greater than 10) are eligible for inclusion, a funnel plot will be used to assess publication bias (Egger 1997).

\section{Data synthesis}

We would only conduct meta-analyses when there are studies of similar comparisons reporting the same outcome measures. For dichotomous data risk ratios and 95\% confidence intervals (Cl) would be combined. For continuous data calculated mean differences and $95 \% \mathrm{Cl}$ would be combined. If continuous data were measured with different instruments (different and not interchangeable units of measure) standardized mean differences would be used. If more than three studies were to be identified a random-effects meta-analysis would be performed. In case where only two or three studies were identified fixed-effect meta-analyses would be performed.

\section{Subgroup analysis and investigation of heterogeneity}

In future updates if sufficient studies (greater than 10) are eligible for inclusion, subgroup analyses according to age, gender and length of the follow-up will be performed.

\section{Sensitivity analysis}

In future updates, if sufficient studies for each outcome and intervention are found, we will undertake sensitivity analysis based on the overall risk of bias.

\section{Summary of findings}

We produced a 'Summary of findings' table for each included study as each investigated a different intervention. Where each study reported main outcomes (e.g. periodontal healing (including extent of radiographic resorption), aesthetics (discolouration), oral health-related quality of life, cost, complications or side effects, tooth survival, pulpal healing, or pain) these were recorded. We used GRADE methods (GRADE 2004) and GRADEpro GDT 2015 software. We assessed the quality of the body of evidence for each comparison and outcome by considering the overall risk of bias for each included study, the directness of the evidence, the inconsistency of the results, the precision of the estimates, and the risk of publication bias. We categorised the quality of each body of evidence as high, moderate, low or very low.

\section{RE S U L T S}

\section{Description of studies \\ Results of the search}

As this is the first version of this review to incorporate a PRISMA flow diagram (Figure 3), only information about searches for the current update are presented, the previous version of the review serves as one particular source of studies. The electronic searches yielded 266 records and an additional two studies (Yong-Ping 2010; Murri Dello Diago 2011) were found from other sources in this update as possibly meeting the inclusion criteria. We screened the title and abstracts of 170 records and assessed eight full-text articles for eligibility. Five articles were translated from Chinese into English (Chen 2000; Han 2010; Huang 2003; Yong-Ping 2010; Zhang 2004). Three studies were excluded, with reasons, bringing the total number of excluded studies (including the five studies from the previous version of this review and one study previously awaiting classification and now excluded) to nine. One study is ongoing (ChiCTR-ICR-15007129) and two are awaiting classification owing to lack of detail about the intervention, how the outcome/ $s$ were determined and/or information about the risk of bias (Han 2010; Zhang 2004). One study reported in two papers was found to fulfil the inclusion criteria of the review bringing the total number of included studies (including the three from the previous version of this review) to four. Summary details are given in the Characteristics of included studies and Characteristics of excluded studies tables. 
Figure 3. Study flow diagram.

3 studies included in previous version of review
266 records identified through database searching for current update
2 additional records identified through other sources for current update

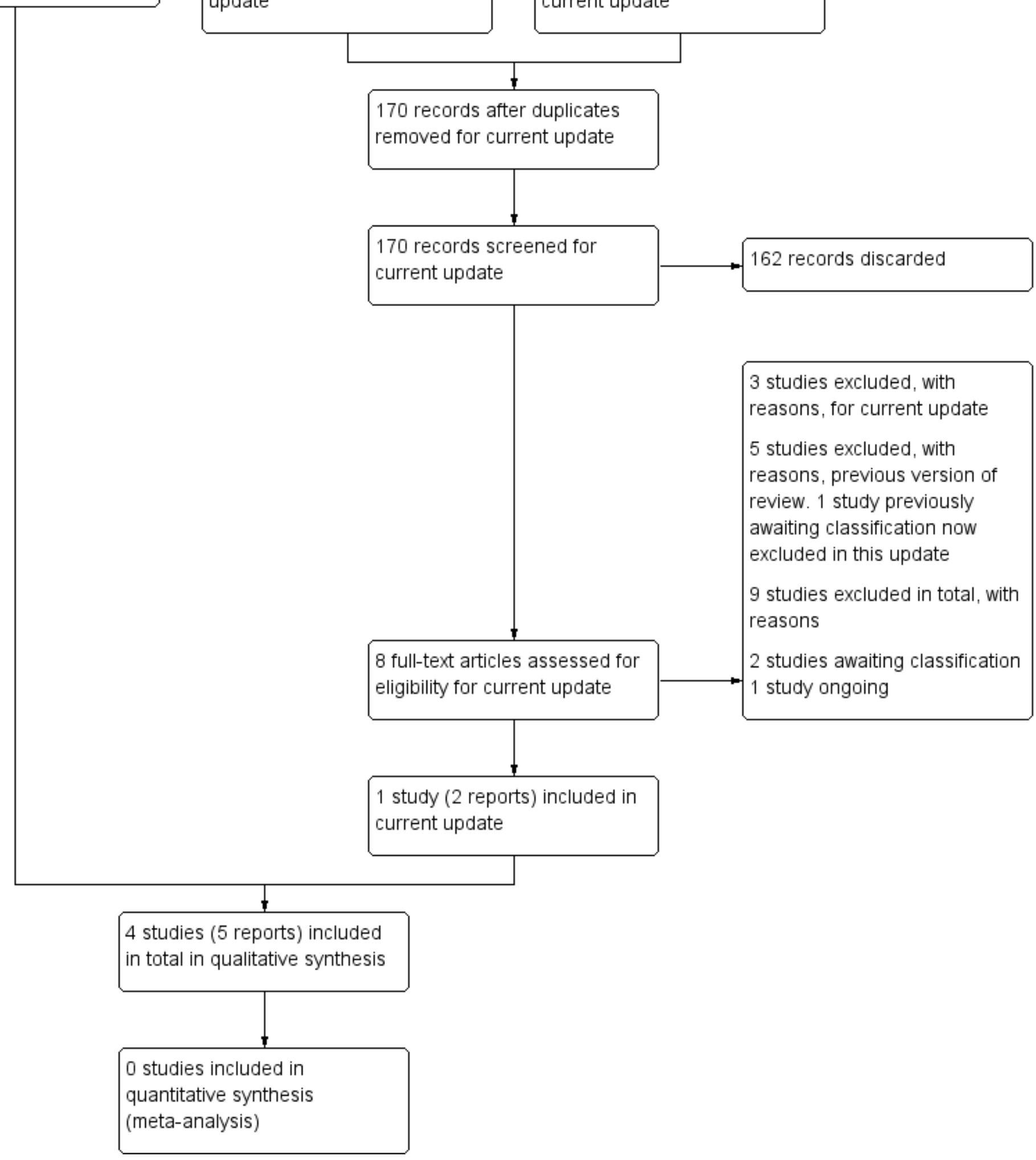




\section{Included studies}

\section{Setting}

Four studies met the inclusion criteria and were included in this review (see Characteristics of included studies table). All were parallel-group trials and all had two arms comparing an experimental arm with a control arm. Two studies were conducted in China (Chen 2000; Loo 2008), one in Italy (Giannetti 2006) and the other in the UK (Day 2012). All studies were conducted in a university clinical setting. The two European studies were conducted by specialists in paediatric dentistry (Day 2012; Giannetti 2006) while it is uncertain if the Chinese studies (Chen 2000; Loo 2008) were undertaken by generalists or specialists. One study used a multicentre approach involving five centres (Day 2012) while the others were all based at a single centre. Recruitment varied in duration from 2 to 7 years. Only one study reported a sample size calculation (Day 2012). Three studies reported no external funding following email correspondence. One study was partially funded by a national body and reported that free materials were obtained from a number of manufacturers (Day 2012).

\section{Participants}

A total of 183 participants with 257 teeth took part in these trials with a range of 19 to 73 participants per study. One study involved children and young adults (Loo 2008), with the other three involving children only. In all studies there were more male participants than female with the ratio varying from 1:0.82 to 1:0.28.

\section{Interventions}

All studies investigated different interventions but each can be categorised into the broader class of attempting to reduce infection or alter the inflammatory response or both. The active medicament or intervention relied on a topical and local effect in three studies (Day 2012; Giannetti 2006; Loo 2008) while the intervention in the fourth study (Chen 2000), hyperbaric oxygen, was administered systemically.

Three trials investigated interventions carried out at the time of replantation (Chen 2000; Giannetti 2006; Loo 2008). In Giannetti 2006 one study group received their intervention at the time of replantation with the other group starting their intervention at day 7. In the fourth study (Day 2012), different topical medicaments were introduced within the root canal at different time points, either between day 0 to 10 for Ledermix or between day 7 to 10 for Ultracal XS.

\section{Outcome measures}

A wide range of outcomes were reported. No study reported all the potential outcomes identified in the methods section. Evaluating the outcomes reported between the different studies was complicated by the use of compound (Chen 2000) and proxy measures (Giannetti 2006) for some outcomes such as periodontal healing.

\section{Excluded studies}

We excluded nine studies (see Characteristics of excluded studies table): three studies were excluded for surrogate study populations or end points (Filippi 2002; Pasini 2006; vonArx 2001); two studies were conference abstracts with no subsequent full publications (Murri Dello Diago 2011; Parodi 1991); for two studies we were unable to retrieve the full text (Huang 2003; Yong-Ping 2010); one study was a retrospective case control study (Tsilingaridis 2015); and finally one study was excluded as it was unclear how participants were allocated to study groups (Coccia 1980).

\section{Risk of bias in included studies}

\section{Allocation}

\section{Sequence generation}

One study (Day 2012) out of four was considered to have adequate sequence generation. For two other studies (Giannetti 2006; Loo 2008) alternation and a quasi-random method were used for sequence generation and therefore these were assessed as at high risk of bias. In the final study it was unclear how sequence generation was determined (Chen 2000).

\section{Allocation concealment}

One study (Day 2012) was considered to have adequate allocation concealment. The rest of the studies, one was assessed as at unclear (Chen 2000) and the other two as at high risk of bias (Giannetti 2006; Loo 2008).

\section{Blinding \\ Performance bias}

For three studies (Chen 2000; Day 2012; Giannetti 2006) the treatment interventions were sufficiently different that it was not possible to blind the clinician and in two studies the patients were aware of the treatment group as well (Chen 2000; Giannetti 2006). We therefore assessed Chen 2000 and Giannetti 2006 as at high risk of performance bias and Day 2012 as at unclear risk of performance bias. One study (Loo 2008) was double-blind with both the patient and clinician blinded to their allocation and was assessed as at low risk of performance bias.

\section{Detection bias}

One study (Loo 2008) was double-blind and therefore rated as at low risk of detection bias. For Day 2012 a senior blinded paediatric dentist assessed the patients clinically and radiographically at 12 months. The authors stated that if the decision regarding periodontal healing differed between the blinded examiner and the treating clinician, then the tooth was considered ankylosed. It was not reported how frequently a disagreement between assessors occurred. However, this methodology was felt unlikely to influence the outcome assessment for one group unfairly over another and therefore we rated the study as at low risk of detection bias. Giannetti 2006 was rated as unclear as although the recruiting clinician reviewing the patient at subsequent assessment visits was blinded to the allocation of the patient, it is uncertain how effective this was as no detail was given in the paper and ideally the two roles should be undertaken by different researchers. There was no blinding in the final study (Chen 2000) and therefore we assessed it as at high risk of detection bias.

\section{Incomplete outcome data}

For two trials (Day 2012; Giannetti 2006) sufficient information was presented in the paper to assess attrition bias. For the other two studies, the final numbers of how many started the trial required further clarification by email correspondence. In one study (Chen 2000 ) the numbers lost were few and similar in each arm. The final study (Loo 2008) had marked disparities in the loss to follow-up 
in the different arms of the study (36\% versus $2 \%$ ), this study was therefore assessed to have a high risk of attrition bias.

\section{Selective reporting}

We assessed one study (Giannetti 2006) as at high risk of reporting bias since the primary outcome measure for our review, periodontal healing, was not reported in the study and this would be a standard outcome measure for such a study. The rest of the studies were at low risk of reporting bias.

\section{Other potential sources of bias}

Two studies (Chen 2000; Loo 2008) were assessed as at unclear risk of other bias owing to the outcomes recorded in the control groups. In one study (Chen 2000) the control group considerably outperformed periodontal healing from another large data set (Andreasen 1995). In the other study (Loo 2008), the tooth loss in the control group was significantly worse than reported from another large data set (Andreasen 1995). For the other two studies (Day 2012; Giannetti 2006) no other sources of bias were identified.

\section{Overall risk of bias}

Three studies (Chen 2000; Giannetti 2006; Loo 2008) had at least one domain where risk of bias was high and therefore we assessed them as at high overall risk of bias. The fourth study (Day 2012) was rated at unclear overall risk of bias. Risk of bias can be viewed graphically in Figure 1; Figure 2.

\section{Effects of interventions}

See: Summary of findings for the main comparison Hyperbaric oxygen compared with control for avulsed and replanted teeth; Summary of findings 2 Ledermix compared with Ultracal for avulsed and replanted teeth; Summary of findings 3 Extra-oral pulp extirpation at day 0 compared with intra-oral extirpation at day 7 for avulsed and replanted teeth; Summary of findings 4 Thymosin alpha 1 compared with control for avulsed and replanted teeth

Each of the interventions aimed to reduce infection or alter the inflammatory response or both at the time of or shortly after the tooth or teeth were replanted. As each intervention was distinctly different, the results and data analysis are presented separately for each study.

\section{Hyperbaric oxygen versus control}

\section{Periodontal healing}

One study at high risk of bias and analysing 69 participants (138 teeth) compared hyperbaric oxygen with control and reported periodontal healing as part of a compound outcome measure at 12 months (Chen 2000). It showed a benefit in favour of the hyperbaric oxygen group (risk ratio (RR) 2.04, 95\% confidence interval (Cl) 1.52 to $2.73, \mathrm{P}<0.00001$ ) (Analysis 1.1). For this outcome measure, 64 out of 73 teeth showed periodontal healing in the hyperbaric oxygen group compared to 28 out of 65 teeth for the control group. The number of patients involved was not reported and as more than one tooth per patient was used, this may lead to an overestimation in the effect between the two interventions (Higgins 2011).

\section{Tooth survival}

Chen 2000 (69 participants, 138 teeth) reported tooth survival at 12 months. For this outcome measure 72 out of 73 teeth showed tooth survival in the hyperbaric oxygen group compared to 53 out of 65 teeth for the control group. They showed a benefit for the hyperbaric oxygen group (RR $1.21,95 \% \mathrm{Cl} 1.07$ to $1.36, \mathrm{P}=0.002$ ) (Analysis 1.2). The number of patients involved was not reported and as more than one tooth per patient was used, this could lead to an overestimation in the effect between the two interventions (Higgins 2011).

\section{Pulpal healing}

Chen 2000 (69 participants, 138 teeth) reported pulpal healing at 12 months. For this outcome measure, 66 out of 73 teeth showed pulp survival in the hyperbaric oxygen group compared to 47 out of 65 teeth for the control group. They showed a benefit for the hyperbaric oxygen group (RR $1.25,95 \% \mathrm{Cl} 1.06$ to $1.48, \mathrm{P}=0.009$ ) (Analysis 1.3). The number of patients involved was not reported and as more than one tooth per patient was used, this may lead to an overestimation in the effect between the two interventions (Higgins 2011).

\section{Adverse effects}

Chen 2000 did not report this outcome. Following email correspondence, study authors reported that no adverse effects were seen although it was uncertain if this was part of the formal assessment or purely anecdotal.

\section{Pain, aesthetics (discolouration), oral health-related quality of life, trauma-related dental anxiety, infraocclusion, cost}

The study in this comparison did not report these outcomes.

\section{Ledermix versus Ultracal}

\section{Periodontal healing}

One study at unclear risk of bias and analysing 22 participants ( 27 teeth) compared Ledermix (day 0 to 10) with Ultracal (day 7 to 10) root canal medicaments following avulsion and replantation (Day 2012). It reported periodontal healing at 12 months showing no difference between the two medicaments at tooth level (RR $1.67,95 \% \mathrm{Cl} 0.80$ to $3.49, \mathrm{P}=0.17$ ) (Analysis 2.1). However, the authors identified that they did not recruit sufficient numbers of participants to meet their power calculation. The number of patients involved was reported and analysis undertaken at a patient as well as a tooth level. However, in none of the calculations was there sufficient evidence to show a benefit for one intervention over the other.

\section{Tooth survival}

Day 2012 reported tooth survival at 12 months with all teeth still present. One tooth in the Ultracal group was extracted at 16 months. Despite root canal treatment, this tooth was diagnosed with persistent symptomatic infection of the root canal. No tooth was extracted or lost in the Ledermix group.

\section{Pulpal healing}

For Day 2012 pulpal healing was not appropriate as root canal treatment was electively undertaken. 


\section{Aesthetics (discolouration)}

Only one study (Day 2012) reported on discolouration. Discolouration was not the primary outcome for this study and therefore the study was not powered to find a difference for this outcome. However at 12 months, Ledermix led to a greater level of patient dissatisfaction with the colour of avulsed and replanted teeth. There were 10 patients in the Ledermix group and 12 patients in the Ultracal group. One patient avulsed three teeth in the Ledermix group and was unhappy with the colour of one of them. At a patient level the size of effect was RR 7.20 (95\% Cl 1.03 to 50.28$)$ to RR 8.40 ( $95 \% \mathrm{Cl} 1.23$ to 57.29 ) depending on which tooth for this patient was entered into the calculation (Analysis 2.3; Analysis 2.4). Discolouration was also measured objectively using photographs and digital software. Over a 12-month period, there was a grey brown darkening of avulsed and replanted teeth in the Ledermix group (mean change from baseline to 12 months, $L^{*}=-5.1, a^{*}=$ $0.3, \mathrm{~b}^{\star}=-1.2$, and $\Delta \mathrm{E}=8.1$ ). During a 12 -month period there was a yellowing of the avulsed and replanted teeth in the Ultracal group $\left(L^{\star}=1.9, a^{\star}=0.3, b^{\star}=3.3\right.$, and $\left.\Delta E=5.4\right)$.

\section{Adverse effects}

Day 2012 used a formal methodology to identify and report adverse effects, with none identified.

\section{Pain, oral health-related quality of life, trauma-related dental anxiety, infraocclusion, cost}

The study in this comparison did not report these outcomes.

\section{Extra-oral pulp extirpation prior to replantation versus intra- oral extirpation at day 7 post-replantation}

\section{Periodontal healing}

One study at high risk of bias and analysing 19 participants compared extra-oral endodontics at day 0 with intra-oral endodontics at day 7 post-replantation (Giannetti 2006). It reported a proxy outcome measure for periodontal healing, namely extent of radiographic root resorption at 12 months. Owing to the prolong extra-alveolar dry time all teeth in this study would be expected to heal by replacement resorption although this was not explicitly reported. Giannetti 2006 reported the number of patients with root resorption at 12 months. Resorption was seen in 1 out of the 10 patients with extra-oral extirpation at day 0 compared to 3 out of 9 patients for intra-oral extirpation at day 7 , RR $1.35(95 \% \mathrm{Cl} 0.81$ to $2.24, P=0.25$ ) (Analysis 3.1). There was insufficient evidence to show a benefit for one intervention over the other.

\section{Pulpal healing}

For Giannetti 2006 this outcome was not appropriate as root canal treatment was electively undertaken.

\section{Adverse effects}

Giannetti 2006 did not report this outcome. Following email correspondence, study authors reported that no adverse effects were seen although it was uncertain if this was part of the formal assessment or purely anecdotal.

Tooth survival, pain, aesthetics (discolouration), oral healthrelated quality of life, trauma-related dental anxiety, infraocclusion, cost

Giannetti 2006 did not report these outcomes.

\section{Thymosin alpha 1 versus control}

\section{Periodontal healing}

One study at high risk of bias and analysing 73 participants compared thymosin alpha 1 with saline for soaking the avulsed tooth for 10 minutes prior to replantation (Loo 2008). It reported periodontal healing at 48 months. It showed a benefit for the thymosin group, with 34 out of 44 teeth showing periodontal healing in the thymosin group compared to 4 out of 29 in the control group, RR $5.60(95 \% \mathrm{Cl} 2.22$ to $14.11, \mathrm{P}=0.0003)$ (Analysis 4.1). The data are presented at a patient level only. Email correspondence confirmed that patients suffering two or more avulsed teeth were excluded from the study.

\section{Tooth survival}

Loo 2008 (73 participants) reported tooth survival at 12 and 48 months. At 12 months, it showed a benefit for the thymosin group, with 42 out 44 teeth showing tooth survival in the thymosin group compared to 19 out of 29 for the control group, RR $1.46(95 \% \mathrm{Cl}$ 1.11 to $1.91, \mathrm{P}=0.007$ ) (Analysis 4.2). At 48 months, the benefit for the thymosin group persisted, with 38 out 44 teeth showing tooth survival in the thymosin group compared to 7 out of 29 for the control group, RR 3.58 ( $95 \% \mathrm{Cl} 1.86$ to $6.89, \mathrm{P}=0.0001)$ (Analysis 4.3). The data are presented at a patient level only.

\section{Pulpal healing}

For Loo 2008 this outcome was not appropriate as root canal treatment was electively undertaken.

\section{Pain}

Only Loo 2008 reported on this outcome at the time of replantation and again at days 1,2 and 5. It reported a benefit in pain scores on day 1 in favour of the thymosin group. No difference was found between the two interventions at the other two time points, day 2 and 5 .

\section{Adverse effects}

Loo 2008 did not report this outcome. Following email correspondence, study authors reported that no adverse effects were seen although it was uncertain if this was part of the formal assessment or purely anecdotal.

\section{Aesthetics (discolouration), oral health-related quality of life, trauma-related dental anxiety, infraocclusion, cost}

None of these outcomes were reported by Loo 2008.

\section{DISCUSSION}

\section{Summary of main results}

We included four studies which reported on interventions for avulsed and replanted permanent teeth. These studies involved 183 patients and 257 teeth. One study involved children and young adults (Loo 2008), with the other three involving children only. Three studies reported on periodontal healing: two at 12 months (Chen 2000; Day 2012) and one at 48 months (Loo 2008). Tooth survival was presented at 12 months for three studies (Chen 2000; Day 2012; Loo 2008) and at 48 months also in one study (Loo 2008). Unfortunately none of the four studies investigated the same intervention. Even the control groups in each study differed with respect to the treatment protocols. Therefore it was not possible 
to combine the results and each study was evaluated individually. In general, each intervention could be grouped in the broader category of reducing infection or modifying the inflammatory response or both.

\section{Hyperbaric oxygen versus control}

On the basis of one trial (Chen 2000), there was very low-quality evidence which supported the benefits of hyperbaric oxygen for avulsed and replanted teeth in respect of periodontal healing, tooth survival, and pulpal healing (Summary of findings for the main comparison).

\section{Ledermix (day 0 to 10) versus Ultracal (day 7 to 10) root canal medicaments following avulsion and replantation}

On the basis of one trial (Day 2012), there was very low-quality evidence which was unable to identify the superiority of one intervention over the other in respect of periodontal healing or tooth survival. Day 2012 did identify a greater level of patient dissatisfaction with the colour of the teeth treated in the Ledermix group compared to the Ultracal group (Summary of findings 2).

\section{Extra-oral endodontics prior to replantation versus intra-oral endodontics at day 7 post-replantation}

On the basis of one trial (Giannetti 2006), there was very low-quality evidence which was unable to identify the superiority of extra-oral pulp extirpation compared to intra-oral extirpation for avulsed and replanted teeth with a dry time of over 60 minutes (Summary of findings 3 ).

\section{Thymosin alpha 1 versus saline for 10 -minute soaking prior to replantation}

On the basis of one trial (Loo 2008), there was very low-quality evidence which supported the benefits of soaking the avulsed tooth in thymosin alpha 1 prior to replantation with respect to periodontal healing and tooth survival (Summary of findings 4).

Based on the very low-quality evidence from these four included studies, we are uncertain whether any one treatment is more beneficial than another for avulsed and replanted permanent teeth.

\section{Overall completeness and applicability of evidence}

There was insufficient evidence to draw any useful conclusions. Failure to follow CONSORT guidance for reporting of randomised controlled trials in three of the studies (Chen 2000; Giannetti 2006; Loo 2008), led to significant work for the review team in contacting the original authors to extract critical information with respect to outcome measures, interventions and potential biases. Each study was focused on avulsed and replanted permanent teeth. A number of the potential interventions outlined in the research objectives were examined including variations in timing of pulp extirpation, types of root canal medicament used, storage of the tooth prior to replantation and follow-up care. A number of different outcomes were reported including periodontal healing, tooth survival, pulpal healing, pain, and aesthetics (discolouration). These last two outcomes are more patient focused but further work is needed to improve the quality and range of outcomes reported. This is a common finding across the dental traumatology literature (Sharif 2015). Importantly the new core outcome set developed for dental traumatology (Kenny 2018) offers an internationally agreed generic and injury-specific set of outcomes including those for avulsed and replanted teeth. The core outcome set not only identifies 'what' outcomes to be collected but also clarifies 'how' and 'when' these outcomes should be collected.

Each of these studies was undertaken in a university/specialist clinic environment with strict follow-up regimens. Moreover some studies required access to specialist equipment such as a hyperbaric oxygen chamber or medicaments which are not normally available in general dental practice. The generalisation of the results to other clinical settings or countries should therefore be considered with caution.

\section{Quality of the evidence}

The body of evidence identified do not allow for a robust conclusion regarding the objectives of the review. The evidence was of very low quality for all reported outcomes. Three studies (Chen 2000; Giannetti 2006; Loo 2008) were at high risk of bias and therefore their results have to be interpreted with caution. The final study (Day 2012) was assessed as having an unclear risk of bias and was also downgraded for imprecision (due to singlestudy comparisons with a small sample size and failure to meet their estimated sample size calculation). The included studies where directly relevant to children and adults with one or more avulsed permanent teeth. However, as already identified some of the treatments provided are unlikely to be available in primary or emergency care settings. Assessment of consistency of results is challenging as each included study explored different interventions and even the control groups followed different protocols. We undertook a detailed search for both published and unpublished studies, with no restrictions on language to limit the risk of publication bias. We searched the reference lists of included studies and contacted many study authors to obtain information that was not included in the published reports. Given that few studies comparing similar interventions were found, funnel plot assessment of publication bias was not undertaken (Higgins 2011). Caution should be exercised when generalising the results of the included trials.

\section{Potential biases in the review process}

One study included in this updated review (Day 2012) was carried out by two of the review authors (Peter Day and Monty Duggal). In order to minimise any favourable interpretation of this study the third review author (Hani Nazzal) who was not involved in this study took the lead in reviewing the study and was supported by a member of the Cochrane Oral Health editorial team (Philip Riley).

\section{Agreements and disagreements with other studies or reviews}

Three systematic reviews (Hinckfuss 2009a; Hinckfuss 2009b; Hinckfuss 2009c) have addressed different aspects of treatment for avulsed and replanted teeth including the timing of pulp extirpation, the prescription of systemic antibiotics, and the duration of splinting. These systematic reviews included study designs that were excluded from this Cochrane Review including retrospective clinical audits and prospective case series. Interestingly, none of the studies included in this Cochrane Review were included in their reviews and vice versa. Therefore it is not possible to compare the results between this Cochrane Review and the three systematic reviews. 


\section{AUTHORS' CONCLUSIONS}

\section{Implications for practice}

Based on the results of the included studies, there is insufficient evidence to support or refute the effectiveness of different interventions for avulsed and replanted permanent front teeth. The overall quality of existing evidence was very low and therefore great caution should be exercised when generalising the results of the included trials. There is urgent need for further well-designed randomised controlled trials.

Until more evidence becomes available clinicians should continue to base their treatment decisions on current expert-based guidelines (BSPD 2012; IADT 2012) in combination with their own clinical experience and the individual circumstances and preferences of their patients or their parent or guardian, or both.

\section{Implications for research}

Unfortunately, as can be seen there are very few studies in the human tooth avulsion literature which can meet the requirements for inclusion in a Cochrane Review. Since the original version of this Cochrane Review, only one further study has been published. Therefore future studies in this area should ensure that they are able to be included when this review is updated again.

Conducting research in this area is difficult for a number of reasons:

- the rarity of the injury,

- the different specialities that are providing the different stages of care for patients suffering avulsion injuries,

- the variability of emergency presentation of patients following avulsion injury,

- the failure by patients to present with sufficient speed that a viable periodontal ligament is still present, and

- the ethical problem of obtaining informed consent in an emergency situation.

This list of problems does not mean that good-quality research is impossible for avulsed and replanted teeth. It does, however, require good planning before undertaking a well-designed study. Good-quality studies require the appropriate financial sponsorship to maintain the enthusiasm of centres to recruit and retain enough participants to ensure the study reaches its power calculation and therefore that a valid conclusion can be drawn from it.

Methodology: a number of editorials (Andreasen 1990; Trope 2003) have urged clinicians and specialist centres to work together to provide sufficient numbers for multicentre research as each centre is unable to provide sufficient cases on its own in a sensible time frame. Giannetti 2006 validated this need due to the small numbers recruited over the 2-year period. The two Chinese studies (Chen
2000; Loo 2008) both showed certain centres in China do see sufficient numbers for a single-centre trial. Although Day 2012 was a multicentre study involving five specialist paediatric dentistry centres, it failed to recruit enough patients. The study authors argued that with better feasibility assessment and external grant funding the researchers would have been able to dedicate more time to the study at each centre which would have helped with recruitment of possible subjects.

Where possible the same speciality should see the patient from acute presentation to review visits, thereby ensuring all relevant information is collected and treatment protocols are followed.

Careful study design and compliance will help to ensure the results are valid. An acceptance amongst investigators that due to the small sample likely to be recruited no more than one variable should be tested in each study.

Outcome measures: recently, an internationally agreed core outcome set has been published for dental traumatology (Kenny 2018). This document outlines 'what' outcomes should be collected for avulsion injuries as well as 'when' and 'how' this information should be collected. Authors planning future avulsion and replantation studies should ensure that the outcomes they propose collecting at least meet these minimum requirements.

Priority areas of future research: this Cochrane Review has identified that there is a need to establish the optimal medicament and duration for soaking the tooth prior to replantation. It appears that this may be able to influence the healing responses and increase the chances of periodontal and pulpal healing. Contenders for further studies are different antibiotics or thymosin alpha 1. Other methods of application such as the use of the root canal space or daily gingival injections for providing slow and ongoing release of medicaments to the surrounding healing tissues or the use of hyperbaric oxygen should be investigated further.

Reporting clinical findings: three of the studies (Chen 2000; Giannetti 2006; Loo 2008) identified in this review would benefit from reporting their trials in guidance with the CONSORT recommendation to ensure transparency and clarity.

\section{ACKNOWLEDGEMENTS}

Search strategy was developed by Anne Littlewood (Information Specialist, Cochrane Oral Health). The review authors would like to thank Luisa Fernandez Mauleffinch (Managing Editor), Philip Riley (Editor) and the Cochrane Oral Health editorial team (Professors Helen Worthington and Jan Clarkson). Thank you to Janet Lear (Cochrane Oral Health) for her attempts to try and retrieve various Chinese papers and to Dr May Wong, Dr Chunjie Li, Professor Zongdao Shi, Professor Hua Chengge, and Dr Liyuan Ma for their support and translation of these papers. We also thank peer reviewers for their comments. 


\section{R E F E R E N C E S}

\section{References to studies included in this review}

Chen $\mathbf{2 0 0 0}$ \{published data only\}

Chen F, Sun H, Jia B. Clinical studies on the use of hyperbaric oxygen in replantation of young permanent teeth. Chinese Journal of Stomatology 2000;35(4):271-3.

\section{Day 2012 \{published data only\}}

Day PF, Duggal MS, High AS, Robertson A, Gregg TA, Ashley PF, et al. Discoloration of teeth after avulsion and replantation: results from a multicenter randomized controlled trial. Journal of Endodontics 2011;37(8):1052-7.

* Day PF, Gregg TA, Ashley P, Welbury RR, Cole BO, High AS, et al. Periodontal healing following avulsion and replantation of teeth: a multicentre randomized controlled trial to compare two root canal medicaments. Dental Traumatology 2012;28(1):55-64.

\section{Giannetti 2006 \{published data only\}}

Giannetti L, Murri A. Clinical evidence and literature to compare two different therapeutic protocols in tooth avulsion. European Journal of Paediatric Dentistry 2006;7(3):122-30.

\section{Loo 2008 \{published data only\}}

Loo WT, Dou YD, Chou WK, Wang M. Thymosin alpha 1 provides short-term and long-term benefits in the reimplantation of avulsed teeth: a double-blind randomized control pilot study. American Journal of Emergency Medicine 2008;26(5):574-7.

\section{References to studies excluded from this review}

Coccia 1980 \{published data only\}

Coccia CT. A clinical investigation of root resorption rates in reimplanted young permanent incisors: a five year study. Journal of Endodontics 1980;6(1):413-20.

\section{Filippi 2002 \{published data only\}}

Filippi A, von Arx T, Lussi A. Comfort and discomfort of dental trauma splints - a comparison of a new device (TTS) with three commonly used splinting techniques. Dental Traumatology 2002;18(5):275-80.

\section{Huang 2003 \{published data only\}}

Huang FM, Zhang AM, Dong FZ. Comparative study on different pulp treatment in acute replanted teeth. Modern Medicine of China 2003;3:627-8.

\section{Murri Dello Diago 2011 \{published data only (unpublished sought} but not used)\}

Murri Dello Diago A, Giannetti L. Tooth avulsion. A RCT on replantation of teeth with extra-oral dry time $>60$ minutes. International Journal of Paediatric Dentistry 2011;21(Suppl 1):176 (Abs No P18-325).

\section{Parodi 1991 \{published data only\}}

Parodi RJ, Esper ME, Artal N. The role of citric acid in dental reimplants of teeth treated for periodontal disease. Journal of Dental Research 1991;70:641 (Abs No 43).
Pasini 2006 \{published data only\}

Pasini S, Bardellini E, Casula I, Flocchini P, Majorana A. Effectiveness of oral hygiene protocol in patients with posttraumatic splinting. European Journal of Paediatric Dentistry 2006;7(1):35-8.

Tsilingaridis 2015 \{published data only\}

Tsilingaridis G, Malmgren B, Skutberg C, Malmgren O. The effect of topical treatment with doxycycline compared to saline on 66 avulsed permanent teeth - a retrospective case-control study. Dental Traumatology 2015;31(3):171-6.

vonArx 2001 \{published data only\}

vonArx T, Filippi A, Lussi A. Comparison of a new dental trauma splint device (TTS) with three commonly used splinting techniques. Dental Traumatology 2001;17(6):266-74.

Yong-Ping 2010 \{published data only\}

Yong-Ping J. Root canal therapy in replantation of tooth due to injury. Acta Medicinae Sinica 2010;3:295-7.

\section{References to studies awaiting assessment}

Han 2010 \{published data only (unpublished sought but not used)\} Han JL, He H, Xu Z, Gu T, Zhang LD, Zhu YQ. Clinical study on prevention root absorption after teeth replantation with Vitapex paste. Shanghai Journal of Stomatology 2010;19(4):346-8.

Zhang 2004 \{published data only (unpublished sought but not used)\}

Zhang QY, Wang XL, Haung LJ. Root canal therapy opportunity in replanted teeth due to injury. Shanghai Journal of Stomatology 2004;13(5):457-8. [PUBMED: PMID:15514883]

\section{References to ongoing studies}

ChicTR-ICR-15007129 \{published data only\}

ChiCTR-ICR-15007129. Effect of platelet-rich fibrin on the periodontal healing of avulsed tooth reimplantation: a randomized-controlled trial. www.chictr.org.cn/ showprojen.aspx?proj=11958 (first received 20 September 2015).

\section{Additional references}

\section{Al Ansary 2009}

Al Ansary MA, Day PF, Duggal MS, Brunton PA. Interventions for treating traumatized necrotic immature permanent anterior teeth: inducing a calcific barrier and root strengthening. Dental Traumatology 2009;25:367-79.

\section{Andersson 1989}

Andersson L, Bodin I, Sorensen S. Progression of root resorption following replantation of human teeth after extended extraoral storage. Endodontics and Dental Traumatology 1989;5(1):38-47. 


\section{Andreasen 1990}

Andreasen JO, Andreasen FM. Dental traumatology: quo vadis. Endodontics and Dental Traumatology 1990;6(2):78-80.

\section{Andreasen 1995}

Andreasen JO, Borum MK, Jacobsen HL, Andreasen FM. Replantation of 400 avulsed permanent incisors. 4. Factors related to periodontal ligament healing. Endodontics and Dental Traumatology 1995;11(2):76-89.

\section{Andreasen 2007}

Andreasen JO, Andreasen FM. Avulsions. In: Andreasen JO, Andreasen FM, Andersson L editor(s). Textbook and Color Atlas of Traumatic Injuries to the Teeth. 4th Edition. Copenhagen: Blackwell Munksgaard, 2007:444-88.

\section{Andreasen 2010}

Andreasen JO, Ahrensburg SS, Tendal B. Inappropriate use of meta-analysis in an evidence-based assessment of the clinical guidelines for replanted avulsed teeth. Timing of pulp extirpation, splinting periods and prescription of systemic antibiotics. Dental Traumatology 2010;26(5):451-2.

\section{Barrett 1997}

Barrett EJ, Kenny DJ. Survival of avulsed permanent maxillary incisors in children following delayed replantation. Endodontics and Dental Traumatology 1997;13(6):269-75.

\section{Berger 2009}

Berger TD, Kenny DJ, Casas MJ, Barrett EJ, Lawrence HP. Effects of severe dentoalveolar trauma on the quality-of-life of children and parents. Dental Traumatology 2009;25(5):462-9.

\section{Borum and Andreasen 2001}

Borum MK, Andreasen JO. Therapeutic and economic implications of traumatic dental injuries in Denmark: an estimate based on 7549 patients treated at a major trauma centre. International Journal of Paediatric Dentistry 2001;11(4):249-58.

\section{BSPD 2012}

Day PF, Gregg TA. Treatment of avulsed permanent teeth in children. UK National Clinical Guidelines in Paediatric Dentistry. www.bspd.co.uk/Portals/0/Public/Files/Guidelines/ avulsion_guidelines_v7_final_.pdf (accessed prior to 14 January 2019).

\section{Burden 1995}

Burden DJ. An investigation of the association between overjet size, lip coverage and traumatic injury to maxillary incisors. European Journal of Orthodontics 1995;17:513-7.

\section{Chadwick 2006}

Chadwick BL, White DA, Morris AJ, Evans D, Pitts NB. Noncarious tooth conditions in children in the UK, 2003. British Dental Journal 2006;200(7):379-84.

\section{Cortes 2002}

Cortes MI, Marcenes W, Sheiham A. Impact of traumatic injuries to the permanent teeth on the oral health-related quality of life in 12-14-year-old-children. Community Dentistry and Oral Epidemiology 2002;30(3):193-8.

\section{Day 2008}

Day PF, Kindelan SA, Spencer J, Kindelan J, Duggal MS. Dental trauma: part 2. Managing poor prognosis anterior teeth treatment options for the subsequent space in a growing patient. Journal of Orthodontics 2008;35(3):143-55.

\section{de Souza 2015}

de Souza RF, Travess H, Newton T, Marchesan MA. Interventions for treating traumatised ankylosed permanent front teeth. Cochrane Database of Systematic Reviews 2015, Issue 12. [DOI: 10.1002/14651858.CD007820.pub3]

\section{Egger 1997}

Egger M, Smith GD, Schneider M, Minder C. Bias in meta-analysis detected by a simple, graphical test. BMJ 1997;315:629-34.

\section{Eilert-Petersson 1997}

Eilert-Petersson E, Andersson L, Sorensen S. Oral injuries in relation to non oral injuries. Swedish Dental Journal 1997;21:55-68.

\section{Fakhruddin 2008}

Fakhruddin KS, Lawrence HP, Kenny DJ, Locker D. Impact of treated and untreated dental injuries on the quality of life of Ontario school children. Dental Traumatology 2008;24:309-13.

\section{Flores 2007}

Flores MT, Andersson L, Andreasen JO, Bakland LK, Malmgren B, Barnett $F$, et al. Guidelines for the management of traumatic dental injuries. II. Avulsion of permanent teeth. Dental Traumatology 2007;23(3):130-6.

\section{Glendor 2001}

Glendor U, Jonsson D, Halling A, Lindqvist K. Direct and indirect costs of dental trauma in Sweden: a 2-year prospective study of children and adolescents. Community Dentistry and Oral Epidemiology 2001;29(2):150-60.

\section{Glendor 2008}

Glendor U. Epidemiology of traumatic dental injuries - a 12-year review of the literature. Dental Traumatology 2008;24(6):603-11.

\section{GRADE 2004}

GRADE Working Group. Grading quality of evidence and strength of recommendations. BMJ 2004;328(7454):1490.

\section{GRADEpro GDT 2015 [Computer program]}

McMaster University (developed by Evidence Prime). GRADEpro GDT. Version accessed 8 March 2018. Hamilton (ON): McMaster University (developed by Evidence Prime), 2015.

\section{Gulinelli 2008}

Gulinelli J, Saiton C, Garcia-Junior I, Panzarini S, Poi W, Sonoda C, et al. Occurrence of tooth injuries in patients treated in hospital environment in the region of Aracatuba, Brazil during a 6-year period. Dental Traumatology 2008;24:640-4. 


\section{Hamilton 1997}

Hamilton FA, Hill FJ, Holloway PJ. An investigation of dentoalveolar trauma and its treatment in an adolescent population. Part 1: the prevalence and incidence of injuries and the extent and adequacy of treatment received. British Dental Journal 1997;182:91-5.

\section{Higgins 2011}

Higgins JP, Green S, editor(s). Cochrane Handbook for Systematic Reviews of Interventions Version 5.1.0 (updated March 2011). The Cochrane Collaboration, 2011. Available from handbook.cochrane.org.

\section{Hinckfuss 2009a}

Hinckfuss SE, Messer LB. An evidence-based assessment of the clinical guidelines for replanted avulsed teeth. Part I: timing of pulp extirpation. Dental Traumatology 2009;25(1):32-42.

\section{Hinckfuss 2009b}

Hinckfuss SE, Messer LB. An evidence-based assessment of the clinical guidelines for replanted avulsed teeth. Part II: prescription of systemic antibiotics. Dental Traumatology 2009;25(2):158-64.

\section{Hinckfuss 2009c}

Hinckfuss SE, Messer LB. Splinting duration and periodontal outcomes for replanted avulsed teeth: a systematic review. Dental Traumatology 2009;25(2):150-7.

\section{IADT 2012}

Andersson L, Andreasen JO, Day P, Heithersay G, Trope M, DiAngelis A, et al. International Association of Dental Traumatology guidelines for the management of traumatic dental injuries: 2 . Avulsion of permanent teeth. Dental Traumatology 2012;28:88-96.

\section{Jacobsen and Andreasen 2001}

Jacobsen I, Andreasen JO. Traumatic injuries - examination, diagnosis and immediate care. In: Koch G, Poulsen S editor(s). Pediatric Dentistry. A Clinical Approach. 1st Edition. Copenhagen: Munksgaard, 2001:351-80.

\section{Kania 1996}

Kania MJ, Keeling SD, McGorry SP, Wheeler TT, King GJK. Risk factors associated with incisor injury in elementary school children. Angle Orthodontist 1996;66:423-32.

\section{Keasberry 2013}

Keasberry J, Munyombwe T, Duggal M, Day PF. A study of factors that influence the number of visits following traumatic dental injuries. British Dental Journal 2013;214:1-8.

\section{Kenny 2018}

Kenny K, Day PF, Sharif MO, Parashos P, Lauridsen E, Feldens CA, et al. What are the important outcomes in traumatic dental injuries? An international approach to the development of a core outcome set. Dental Traumatology 2018;34(1):4-11. [DOI: 10.1111/edt.12367]

\section{Kinirons 2000}

Kinirons MJ, Gregg TA, Welbury RR, Cole BOI. Variations in the presenting and treatment features in reimplanted permanent incisors in children and their effect on the prevalence of root resorption. British Dental Journal 2000;189(5):263-6.

\section{Lauridsen 2012}

Lauridsen E, Hermann NV, Gerds TA, Kreiborg S, Andreasen JO. Pattern of traumatic dental injuries in the permanent dentition among children, adolescents and adults. Dental Traumatology 2012;28:358-63.

\section{Lee and Divaris 2009}

Lee JY, Divaris K. Hidden consequences of dental trauma: the social and psychological effects. Paediatric Dentistry 2009;31:96-101.

\section{Lefebvre 2011}

Lefebvre C, Manheimer E, Glanville J. Chapter 6: Searching for studies. In: Higgins JP, Green S, editor(s). Cochrane Handbook for Systematic Reviews of Interventions Version 5.1.0 (updated March 2011). The Cochrane Collaboration, 2011. Available from handbook.cochrane.org.

\section{Malmgren 2002}

Malmgren B, Malmgren O. Rate of infra-position of reimplanted ankylosed incisors related to age and growth in children and adolescents. Dental Traumatology 2002;18(1):28-36.

\section{Marcenes and Ryda 2007}

Marcenes W, Ryda U. Socio-psychological aspects of traumatic dental injuries. In: Andreasen JO, Andreasen FM, Andersson L editor(s). Textbook and Color Atlas of Traumatic Injuries to the Teeth. 4th Edition. Oxford: Blackwell Munksgaard, 2007:197-206.

\section{Nguyen 2004}

Nguyen PM, Kenny DJ, Barrett EJ. Socio-economic burden of permanent incisor replantation on children and parents. Dental Traumatology 2004;20(3):123-33.

\section{Pitts 2015}

Pitts N, Chadwick B, Anderson T, Health and Social Care Information Centre. Children's Dental Health Survey 2013. Report 2: Dental disease and damage in children. England, Wales and Northern Ireland. http://content.digital.nhs.uk/ catalogue/PUB17137/CDHS2013-Report2-Dental-Disease.pdf (accessed prior to 14 January 2019).

\section{Porritt 2011}

Porritt JM, Rodd HD, Ruth Baker S. Quality of life impacts following childhood dento-alveolar trauma. Dental Traumatology 2011;27(1):2-9.

\section{Rodd 2010}

Rodd HD, Barker C, Baker SR, Marshman Z, Robinson PG. Social judgements made by children in relation to visible incisor trauma. Dental Traumatology 2010;26(1):2-8. 


\section{Rodd 2011}

Rodd HD, Marshman Z, Porritt J, Bradbury J, Baker SR. Oral health-related quality of life of children in relation to dental appearance and educational transition. British Dental Journal 2011;211(2):E4.

\section{Royal College of Surgeons 1997}

Royal College of Surgeons of England. Faculty of Dental Surgery. National Clinical Guidelines 1997. www.rcseng.ac.uk/dentalfaculties/fds/publications-guidelines/clinical-guidelines/ (accessed prior to 14 January 2019).

\section{Sharif 2015}

Sharif MO, Tejani-Sharif A, Kenny K, Day PF. A systematic review of outcome measures used in clinical trials of treatment interventions following traumatic dental injuries. Dental Traumatology 2015;31(6):422-8.

\section{Trope 2003}

Trope M. Let's band together for a brighter future. Dental Traumatology 2003;19(1):1.

\section{Vlok 2011}

Vlok JL, Worthington EM, Hindson JA, Davidson LE, Thomson WM, Drummond BK. Young people's perceptions of photographs of dental trauma. Dental Traumatology 2011;27(2):109-12.

\section{CHARACTERISTICS OF STUDIES}

Characteristics of included studies [ordered by study ID]

\section{Wong and Kolokotsa 2004}

Wong FS, Kolokotsa K. The cost of treating children and adolescents with injuries to their permanent incisors at a dental hospital in the United Kingdom. Dental Traumatology 2004;20(6):327-33.

\section{Wright 2007}

Wright G, Bell A, McGlashan G, Vincent C, Welbury R. Dentoalveolar trauma in Glasgow: an audit of mechanism and injury. Dental Traumatology 2007;23(4):226-31.

\section{References to other published versions of this review \\ Day 2007}

Day P, Duggal M. Interventions for treating traumatised permanent front teeth: avulsed (knocked out) and replanted. Cochrane Database of Systematic Reviews 2007, Issue 2. [DOI: 10.1002/14651858.CD006542]

\section{Day 2010}

Day P, Duggal M. Interventions for treating traumatised permanent front teeth: avulsed (knocked out) and replanted. Cochrane Database of Systematic Reviews 2010, Issue 1. [DOI: 10.1002/14651858.CD006542.pub2]

* Indicates the major publication for the study

Chen 2000

Methods Trial design: single centre, parallel, 2-arm RCT Location: School of Stomatology, Fourth Military Medical University, Xi-an, China Type of centre: university dental school Recruitment period: July 1996 to June 1999

Funding source: no external funding was received

Participants Inclusion criteria: not reported in paper - subsequent email correspondence provided the following list of inclusion criteria: all avulsion injuries in young permanent teeth that had no fracture or crack and without coincident maxillofacial or general severe injuries

Exclusion criteria: not reported for individual groups

Age at baseline: not reported for individual groups, for both groups age was a mean of 9.4 years (SD 3)

Gender: not reported for individual groups, for both groups gender split was 38 males with 89 teeth and 31 females with 49 teeth

Ethnicity: not reported

Number randomised: not reported, although in subsequent email correspondence further information was provided with regards to the number lost to follow-up (2, both from control group) and number refusing each treatment ( 2 in hyperbaric oxygen group and 1 in control group). The number of teeth this involved was not reported 
Chen 2000 (Continued)

Number evaluated: 138 teeth in 69 patients (hyperbaric oxygen group: 73 teeth in 35 patients; control group: 65 teeth in 34 patients)

Interventions

Comparison: hyperbaric oxygen versus control

Hyperbaric oxygen ( $n=73$ teeth in 35 patients): 40 minutes pure oxygen then 10 minutes air and then 40 minutes pure oxygen in a $0.25 \mathrm{MPa}$ (2.15 ATA) compression chamber

Control ( $n=65$ teeth in 34 patients): no further treatment beyond standard protocol described below

Standard treatment for both groups: all patients received a standardized treatment protocol of gently cleaning of the tooth in $0.9 \%$ normal saline solution and then immersion for 20 minutes in gentamycin sulphate $(4 \times 107 \mathrm{U} / \mathrm{L})$ prior to replantation. The teeth were then splinted with arch bars for 1 to 2 months. No elective root canal treatment was started. If a tooth was diagnosed with pulp necrosis, endodontic treatment was commenced. No details of the endodontic protocol was provided

Duration of treatment: hyperbaric oxygen group received this treatment once a day for the first 10 days after the injury

Outcomes

For each tooth the following outcome measures were reported at 12 months: periodontal healing, pulp healing, and tooth loss. Each outcome was relevant to this review

In addition, a compound outcome criterion was used. This classified healing as:

- complete success: teeth with normal pulp vitality, periodontal membrane healed, no root resorption and no tooth mobility

- acceptable success: teeth with pulp necrosis and endodontics performed, periodontal membrane attachment or bone ankylosis (replacement resorption), mild root resorption without obvious mobility, replanted tooth will remain for relatively long time

- failure: teeth with pulp necrosis and endodontics performed, periodontal fibrous healing, root resorption with obvious mobility, replanted tooth will be lost in short time

Periodontal healing was not reported as an individual outcome measure. The data for the number of teeth classified with 'complete success' were used for this outcome measure as periodontal healing was 1 of the criteria for it. This may underestimate the number of teeth with periodontal healing as this can occur without pulpal healing but was the safest approach to take for the data presented

Notes Sample size calculation: no sample size reported

\section{Risk of bias}

Bias Authors' judgement Support for judgement

Random sequence genera- Unclear risk tion (selection bias)

Quote: from email correspondence "the method of randomisation is sealed envelopes, however, if the patients did not accept our recommendation, the envelop was put back to our basket. You know, the hyperbaric oxygen treatment need a lot of money. We cannot decide it for our patients"

Comment: sealed envelopes used. Sequence generation not reported in paper or from correspondence

Allocation concealment Unclear risk (selection bias)
Quote: from email correspondence "After the basic treatment of the patient, we choose a envelop, it tells us which group this case should go into. If the patient reject the arrangement, he will exclude into our final analysis"

Comment: no information was provided if the envelopes were opaque or sequentially numbered. It is uncertain what happened with envelopes if the patient rejected the arrangement and whether they were discarded or reused 


\section{Chen 2000 (Continued)}

Blinding of participants and personnel (perfor-

High risk mance bias)

All outcomes
The treatment intervention was sufficiently different that it was not possible to blind the clinician or patient

\section{Blinding of outcome as- High risk sessment (detection bias)}

All outcomes

\begin{abstract}
Quote: from email correspondence "No. It should be, however, we only have several clinicians in our clinic, we know exactly which is which"
\end{abstract}

Comment: clinicians were aware which group the patient had been allocated to

Incomplete outcome data Low risk

(attrition bias)

Comment: not reported, although in subsequent email correspondence further information was provided with regards to the number lost to follow-up (2, both from control group) and number refusing each treatment ( 2 in hyperbaric oxygen group and 1 in control group). The number of teeth this involved was not reported

Comparability of groups provided by email for all subjects. For some criteria, however, information was provided for the entire study not itemised to individual group
The outcome measures used were conventional but were grouped together in an unusual way to provide a compound outcome. It was not possible to tease out individual outcomes, for example periodontal healing. Periodontal healing was not reported as an individual outcome measure. The data for the number of teeth classified with 'complete success' were used for this outcome measure as periodontal healing was 1 of the criteria for it. This may underestimate the number of teeth with periodontal healing as this can occur without pulpal healing but was the safest approach to take for the data presented

Other bias Unclear risk

High levels of periodontal healing (71\%) were reported for the control group at 12 months. Other published avulsion and replantation studies report a lower prevalence of periodontal healing for teeth with equivalent extra-times (information provided by email - 49 had extra-alveolar time of 0.5 to 3 hours and 16 teeth had extra-alveolar time of 3 to 8 hours). However, in the control group in this study, teeth were soaked in gentamycin for 20 minutes prior to replantation which differs from current protocols outlined by international guidelines

Type of centre: predominantly university dental hospitals - all specialist paediatric dentistry departments

Recruitment period: July 2005 and December 2008

Funding source: partial funding from a Department of Health grant; materials and equipment were provided by 3 pharmaceutical companies

\section{Participants}

Inclusion criteria: avulsion injury had to be permanent dentition; aged less than 16 years; completed root length (with/without open apex); no more than 20 minutes dry extra-alveolar storage time before replantation occurred; no more than 60 minutes wet extra-alveolar time before replantation occurred (combinations of dry and wet were acceptable e.g. 50 minutes in milk plus 5 minutes dry time or 20 minutes dry time plus 40 minutes in milk); no previous endodontic treatment

Exclusion criteria: not reported 
Day 2012 (Continued)

Age at baseline: Ledermix: mean 12.8 years (SD 2.2); Ultracal XS: mean 12 years (SD 1.9)

Gender: Ledermix: 50\% males; Ultracal XS: 67\% males

Ethnicity: not reported

Number randomised: 28 patients (Ledermix: 13; Ultracal XS: 15) - 5 excluded as it transpired that they did not meet the inclusion criteria, 1 lost to follow-up

Number evaluated: 22 patients ( 27 teeth) (Ledermix: 10 patients (12 teeth); Ultracal XS: 12 patients (15 teeth))

Ledermix $(n=13)$ : replantation followed by pulp extirpation and intra-canal dressing with Ledermix within the first 10 days

Ultracal XS ( $n=15)$ : replantation followed by pulp extirpation at day 7 to 10 and intra-canal dressing with Ultracal XS

Standard treatment for both groups: in all but 1 case, acute replantation and splinting was undertaken outwith the university dental hospital. These patients were only included as accurate information of this acute care was available and followed current International Association of Dental Traumatology guidelines

At the day 60-90 appointment, the root canal medicament, in both groups, was replaced by Ultracal XS following a standard debridement technique with copious sodium hypochlorite and gentle hand instrumentation. At 6 months following the injury, where there was no sign of infection or active resorption, cold lateral condensation with gutta percha and Tubliseal was used for definitive obturation

Duration of treatment - duration of first inter-canal dressing: Ledermix: mean 70 days (SD 12.2); Ultracal XS: mean 74 days (SD 21.4)

Outcomes

Periodontal healing, discolouration of teeth, tooth loss. Each outcome was relevant to this review and reported at 12 months

Notes Sample size calculation: at a 5\% significance level and 90\% power, 19 participants per group were required. This sample size was not achieved

\section{Risk of bias}

\begin{tabular}{lll}
\hline Bias & Authors' judgement & Support for judgement \\
\hline $\begin{array}{l}\text { Random sequence genera- } \\
\text { tion (selection bias) }\end{array}$ & Low risk & $\begin{array}{l}\text { Quote: "The randomization process was carried out by the Biostatistics De- } \\
\text { partment, University of Leeds. A block randomization method was used to } \\
\text { generate a randomization sequence for each of the centres" }\end{array}$ \\
& $\begin{array}{l}\text { Comment: central randomisation by a specialised unit } \\
\text { Allocation concealment } \\
\text { (selection bias) }\end{array}$ & Low risk \\
& $\begin{array}{l}\text { Quotes: "Randomization codes were sealed within opaque envelopes, by the } \\
\text { department secretary, with a sequential number placed on the outside. The } \\
\text { randomization envelopes were then grouped into numerical order and placed } \\
\text { within the avulsion treatment box that was located in a secure area of each } \\
\text { clinic" and "The block size was unknown to any clinician involved in the study" } \\
\text { Comment: trial investigators would not have been able to foresee and influ- } \\
\text { ence the sequence of treatment assignments }\end{array}$
\end{tabular}

\begin{tabular}{|c|c|c|}
\hline $\begin{array}{l}\text { Blinding of participants } \\
\text { and personnel (perfor- } \\
\text { mance bias) }\end{array}$ & Unclear risk & $\begin{array}{l}\text { The treatment intervention was sufficiently different that it was only possible } \\
\text { to blind the patient }\end{array}$ \\
\hline
\end{tabular}


Day 2012 (Continued)

All outcomes

\section{Blinding of outcome as- Low risk} sessment (detection bias)

All outcomes
For the primary outcome of periodontal healing, although the outcome assessor was blinded to treatment assignment they compared diagnoses with the original treating clinician. Any disagreement led to a diagnosis of failure of periodontal healing which may have led to a bias towards the null. It was not reported how frequently a disagreement between assessors occurred. However, this methodology was felt unlikely to influence the outcome assessment for 1 group unfairly over another

For the secondary outcome of tooth discolouration, the children are unlikely to be influenced by the treatment assignments in their assessment of satisfaction. The other measurements were made by computer software, and therefore unbiased

Incomplete outcome data Low risk (attrition bias)

Attrition rate was similar in each group. Reasons were reported and these were not related to either of the treatments

All outcomes

Selective reporting (re- Low risk Appropriate outcomes were reported in full

porting bias)

Other bias Low risk No other bias was identified

Giannetti 2006

Trial design: single centre, parallel, 2-arm RCT
Location: University Dental School Modena, Italy
Type of centre: university dental hospital - specialist paediatric dentistry department
Recruitment period: January 2004 to January 2006
Funding source: no external funding was received

Participants

Inclusion criteria: avulsion injury to the permanent dentition; where the extra-oral dry time was longer than 60 minutes

Exclusion criteria: a number of specific categories of patients were excluded, including: decompensated diabetics, acute or chronic systemic disease, mentally incompetent, patients in advance stages of pregnancy or nursing and on medication that could interfere with healing of the gingival tissues

Age at baseline: not reported for individual groups, for both groups age was 11.4 years (SD 3)

Gender: not reported for individual groups, for both groups 11 males and 9 females were recruited

Ethnicity: not reported

Number randomised: 20

Number evaluated: 19 patients (intra-oral obturation: 9; extra-oral obturation: 10)

Interventions

Comparison: intra-oral extirpation versus extra-oral extirpation

Intra-oral obturation $(n=10)$ : this group received pulp extirpation at 1 week intra-orally and dressing with non-setting calcium hydroxide. At 2 weeks the dressing was removed and the tooth was obturated with gutta percha 
Extra-oral obturation $(n=10)$ : this group received endodontic treatment with obturation with gutta percha carried out extra-orally prior to replantation on day 0

Standard treatment for both groups: all patients received a standardized treatment protocol of removal of any surface contamination from the root using a "constant irrigation of salt solution", replantation under local anaesthetic, flexible splinting for 14 days, $0.2 \%$ chlorhexidine mouthwash ( 2 to 3 times a day for 14 days), amoxicillin and clavulanic acid antibiotics for 6 days, but dose and frequency were not reported

Duration of intervention: intra-oral obturation: 14 days; extra-oral obturation: 0 days

Outcomes Extent of root resorption (a proxy measure for periodontal healing). This outcome was relevant to this review and reported at 12 months

Notes Sample size calculation: no sample size calculation was reported

\title{
Risk of bias
}

\begin{tabular}{lll}
\hline Bias & Authors' judgement & Support for judgement \\
\hline $\begin{array}{l}\text { Random sequence genera- } \\
\text { tion (selection bias) }\end{array}$ & High risk & $\begin{array}{l}\text { Quote: "randomly divided into groups with a casual method influenced by the } \\
\text { physician or the patients condition" } \\
\text { Comment: following email correspondence, however, it was found that alter- } \\
\text { nation was used }\end{array}$ \\
\hline $\begin{array}{l}\text { Allocation concealment } \\
\text { (selection bias) }\end{array}$ & High risk & $\begin{array}{l}\text { Comment: following email correspondence, the recruiting clinician knew } \\
\text { which group the patient was to be recruited to. Allocation to treatment groups } \\
\text { was on a patient basis }\end{array}$ \\
\hline
\end{tabular}

\begin{tabular}{|c|c|c|}
\hline $\begin{array}{l}\text { Blinding of participants } \\
\text { and personnel (perfor- }\end{array}$ & High risk & $\begin{array}{l}\text { The treatment intervention was sufficiently different that it was not possible to } \\
\text { blind the clinician or the patient }\end{array}$ \\
\hline
\end{tabular}
mance bias)

All outcomes

Blinding of outcome as-
sessment (detection bias)

All outcomes

\begin{abstract}
Comment: following email correspondence, the recruiting clinician reviewing the patient at subsequent assessment visits was blinded to the allocation of the patient. It is uncertain how effective this was as no detail was given in the paper and the 2 roles should be undertaken by different people
\end{abstract}

$\begin{array}{ll}\begin{array}{l}\text { Incomplete outcome data } \\ \text { (attrition bias) }\end{array} & \begin{array}{l}\text { Comment: attrition rates were reported with } 1 \text { patient lost from the intra-oral } \\ \text { obturation group prior to the 12-month review. The reason for this was not re- } \\ \text { All outcomes }\end{array} \\ \begin{array}{l}\text { ported and so it is unknown if patient failed to return or the tooth had been } \\ \text { lost }\end{array}\end{array}$

Selective reporting (re- High risk
porting bias)

Comment: the primary outcome measure for this Cochrane Review - periodontal healing, was not reported. This would be a standard outcome measure for such a study even when all teeth would be expected to heal by replacement resorption as a result of the prolonged extra-oral dry time

\begin{tabular}{ll}
\hline Other bias $\quad$ Low risk & $\begin{array}{l}\text { Although not reported in the paper, the study author has provided further in- } \\
\text { formation about the groups' comparability }\end{array}$
\end{tabular}

Loo 2008

$\begin{array}{ll}\text { Methods } & \text { Trial design: single centre, parallel, 2-arm RCT } \\ & \text { Location: university dental school, Sichuan, China }\end{array}$


Loo 2008 (Continued)

Type of centre: university dental school

Recruitment period: June 2000 to June 2007

Funding source: no external funding was received

Inclusion criteria: not reported
Exclusion criteria: not reported
Age at baseline: not reported for individual groups, for both groups mean age was 16.9 years (SD 3.8)
Gender: not reported for individual groups, for both groups there were 16 females and 57 males
Ethnicity: not reported
Number randomised: 90 patients
Number evaluated: 73 patients

Interventions Comparison: thymosin alpha 1 versus control (saline)

Thymosin alpha $1(n=45)$ : following the pulp extirpation and obturation, the tooth was immersed for 10 minutes in thymosin alpha $(1.6 \mathrm{mg})$ and then the thymosin alpha was used to wash out the socket prior to replantation. Following replantation and splinting the patient was seen every day until day 7 , for the injection of $0.2 \mathrm{~mL}$ of thymosin alpha into the gingival tissues

Control $(n=45)$ : following the pulp extirpation and obturation, the tooth was immersed for 10 minutes in saline and then the saline was used to wash out the socket prior to replantation. Following replantation and splinting the patient was seen every day until day 7 , for the injection of $0.2 \mathrm{~mL}$ of saline into the gingival tissues

Standard treatment for both groups: all patients received a standardized treatment protocol of washing of the tooth in $0.9 \%$ normal saline for 5 minutes. Extra-orally the pulp was then extirpated and obturated with gutta percha while the periodontal ligament was kept moist with saline. The tooth was replanted under local anaesthetic and splinted with a semirigid fibre splint for 10 days. The occlusion was adjusted to prevent contact with the opposing teeth. Amoxicillin ( $250 \mathrm{mg} 3$ times a day for 3 days was prescribed) together with $0.12 \%$ chlorhexidine mouthwash every 4 hours for 7 days

Duration of treatment: duration of daily gingival tissue injects was 7 days

Outcomes

Outcomes reported included periodontal healing (reported at 48 months) and tooth loss (reported at 12 and 48 months), which were both relevant to this review. A number of short-term outcomes were also reported but only the self-reported measure of pain (reported at day 1, 2 and 5 post-replantation), was an outcome relevant to this review

Notes Sample size calculation: no sample size was reported

\section{Risk of bias}

\begin{tabular}{lll}
\hline Bias & Authors' judgement & Support for judgement \\
\hline $\begin{array}{l}\text { Random sequence genera- } \\
\text { tion (selection bias) }\end{array}$ & High risk & $\begin{array}{l}\text { Quote: from email correspondence "the patients had been recruited with odd } \\
\text { number for thymosin and even number for control by a time schedule" }\end{array}$ \\
\hline $\begin{array}{l}\text { Allocation concealment } \\
\text { (selection bias) }\end{array}$ & High risk & $\begin{array}{l}\text { Comment: with quasi-random methods, allocation concealment is not usually } \\
\text { possible. Furthermore, it is unclear how effective allocation concealment was } \\
\text { owing to the unequal loss to follow-up in the } 2 \text { groups }\end{array}$ \\
\hline
\end{tabular}


Loo 2008 (Continued)

Blinding of participants Low risk This study was double-blinded and therefore it was possible to blind the paand personnel (perfortient and clinician

All outcomes

\begin{tabular}{|c|c|c|}
\hline $\begin{array}{l}\text { Blinding of outcome as- } \\
\text { sessment (detection bias) }\end{array}$ & Low risk & $\begin{array}{l}\text { Comment: double-blinded, patient allocation was only broken after } 48 \text { - } \\
\text { months review }\end{array}$ \\
\hline
\end{tabular}

Incomplete outcome data High risk (attrition bias)

All outcomes

\begin{abstract}
Comment: the paper only reported on the patients retained at 48 months. Following email correspondence 90 subjects were recruited with 45 in each group. There was $36 \%$ loss to follow-up in control group and $2 \%$ in the experimental group. $90 \%$ of these patients failed to attend after their initial replantation visit. This difference in loss to follow-up between the 2 groups is a concern and a potential for bias in the study
\end{abstract}

\begin{tabular}{lll}
\hline $\begin{array}{l}\text { Selective reporting (re- } \\
\text { porting bias) }\end{array}$ & Low risk & $\begin{array}{l}\text { Comment: selective reporting of outcome variables does not appear to have } \\
\text { taken place, however, there was only a limited description (paper and email) } \\
\text { of how long-term dental outcomes were assessed. No study protocol was seen } \\
\text { Short-term outcomes were well reported }\end{array}$ \\
\hline Other bias & Unclear risk & $\begin{array}{l}\text { Comment: high levels of tooth loss were reported in the control group at } 12 \\
\text { months (34\%) and } 36 \text { months (76\%). Other published avulsion and replanta- } \\
\text { tion studies report a lower prevalence of tooth loss at these time points }\end{array}$ \\
\hline
\end{tabular}

$\mathrm{ATA}=$ atmosphere absolute; $\mathrm{MPa}=$ megapascal pressure unit; $\mathrm{RCT}=$ randomised controlled trial, $\mathrm{SD}=$ standard deviation .

\section{Characteristics of excluded studies [ordered by study ID]}

\begin{tabular}{ll}
\hline Study & Reason for exclusion \\
\hline Coccia 1980 & Thanks to the study author for his time spent in replying to our questions. This appeared to be a \\
quasi-randomised trial, but there were considerable concerns with regards to randomisation and & allocation concealment as attempts were made to ensure equal numbers were assigned to each \\
group. There were multiple interventions and it was unclear which patients had been allocated to \\
which study group. Finally the outcomes were difficult to follow with regards to which intervention \\
was responsible for what. No clear protocol or flow diagram was provided for the treatments re- \\
ceived by each group
\end{tabular}

Filippi 2002

RCT, well conducted study at low risk of bias investigating sensitivity of splinted teeth, irritation of gingival margins, irritation of the lips, impairment of speech, eating and oral hygiene. Although these parameters are present in both primary and secondary outcomes of this Cochrane Review the study was not included as participants were adults with no dental trauma and therefore this was felt not to be a valid comparison

\begin{tabular}{ll}
\hline Huang 2003 & Full text of paper was not retrievable \\
\hline Murri Dello Diago 2011 & Abstract to conference proceedings, we could not locate subsequent publication \\
\hline Parodi 1991 & Abstract to conference proceedings, we could not locate subsequent publication \\
\hline Pasini 2006 & $\begin{array}{l}\text { RCT, intervention investigated was the effect of multiple hygiene visits with a hygienist between } \\
\text { weeks } 1 \text { and } 6 \text { following different traumatic injuries including avulsions. The control group re- } \\
\text { ceived no hygiene visit. The study was well conducted with a low risk of bias, however, the out- } \\
\text { come measure related to plaque scores. It is unknown how the outcome chosen relates to the out- }\end{array}$
\end{tabular}




\begin{tabular}{ll}
\hline Study & Reason for exclusion \\
\hline comes identified for this review. To our knowledge, no causal link between plaque scores and the \\
healing of avulsed and replanted teeth has been reported to date
\end{tabular}

Tsilingaridis 2015

A retrospective case-control study design which compared the outcomes of avulsed and replanted teeth treated with different protocols depending on which dental clinic the patient attended

vonArx 2001

$\mathrm{RCT}$, well conducted study at low risk of bias investigating tooth mobility, probing depths, presence of plaque and bleeding on probing for 4 types of trauma splint. These outcome measures were considered as surrogate endpoints as no casual link has been shown between these variables and the healing of avulsed and replanted teeth. Participants were adults with no dental trauma and therefore was not considered a valid comparison

$\mathrm{RCT}=$ randomised controlled trial.

Characteristics of studies awaiting assessment [ordered by study ID]

Han 2010

\begin{tabular}{ll}
\hline Methods & RCT \\
\hline Participants & 30 patients were treated between 2003 and 2006 (aged 12 to 48 years, 24 males and 6 females) with \\
& 36 avulsed permanent upper incisors. Avulsed teeth were replanted within 5 hours from trauma. \\
The roots of the avulsion teeth were fully developed
\end{tabular}

Interventions

Following avulsion, the teeth and the sockets were rinsed with saline, after which the teeth were replanted in the sockets under local anaesthesia. The criteria of replantation were no occlusal interference and no gingival blanching. Traumatised teeth were fixed with $3 \mathrm{M}$ resin and $0.88 \mathrm{~mm}$ stainless wires (in 1:2 ratio of trauma teeth/health teeth). Antibiotics and oral hygiene instruction were given after surgery. After 2 weeks, pulpal tissues were extirpated, root canal prepared and irrigated with saline and then filled with thymol paper point for 1 week. Then group A was treated with calcium hydroxide paste for temporary root canal filling, while group B with Vitapex paste root canal filling, and the root canal was covered with zinc-phosphate cement and glass ionomer in sequence

Outcomes After 1.5 years, a permanent root canal filling was placed. Criteria for evaluating the treatment effect

Success: there was no self-conscious symptom, percussive pain and swelling of the gum. X-ray showed no root absorption (or superficial root absorption according to the Andreasen's classification on root absorption) and no abnormal appearance caused by periapical lesions

Failure

Clinically: obvious mobility, pain on percussion, gingival swelling

Radiographically: replacement or inflammatory root resorption according to the Andreasen's classification on root absorption or appearance of periapical lesion

Notes

Kindly translated by Cochrane translating team (Professor Zongdao Shi, Professor Hua Chengge and Dr Liyuan Ma). Further email contact was undertaken to clarify the full nature of the intervention (e.g. what antibiotics was used, was mouthwash used, how long were the teeth splinted for, what is root absorption, how was repair-related resorption categorised, and what periapical appearance determined a failure), and to explore questions related to risk of bias. No reply received from the study authors, emails sent in 2016 
Zhang 2004

\begin{tabular}{|c|c|}
\hline Methods & $\mathrm{RCT}$ \\
\hline Participants & $\begin{array}{l}\text { Avulsed permanent teeth replanted within } 3 \text { hours. Age range from } 10 \text { to } 42 \text { years old. } 42 \text { partici- } \\
\text { pants with } 49 \text { teeth }\end{array}$ \\
\hline \multirow[t]{5}{*}{ Interventions } & $\begin{array}{l}\text { Group A }(n=16) \text { : pulp extirpation before replantation, and the root canal was filled with calcium } \\
\text { hydroxide. Root canal was completed after half a year }\end{array}$ \\
\hline & $\begin{array}{l}\text { Group B }(n=18) \text { : pulp extirpation } 1 \text { week after replantation and the root canal was filled with calci- } \\
\text { um hydroxide. Root canal was completed after half a year }\end{array}$ \\
\hline & $\begin{array}{l}\text { Group C ( } n=15) \text { : replantation directly, pulp extirpation and the root canal was filled with calcium } \\
\text { hydroxide if there was pulp disease. Root canal was completed after half a year }\end{array}$ \\
\hline & $\begin{array}{l}\text { Standard treatment protocol for groups: avulsed tooth was washed by } 0.9 \% \text { normal saline, and im- } \\
\text { mersed by chloromycetin for } 10 \text { minutes, and stored in DM solution. The donor site was irrigated } \\
\text { by } 3 \% \text { hydrogen peroxide and } 0.9 \% \text { normal saline. The tooth was replanted and fixed to at least } 3 \\
\text { healthy teeth on each site }\end{array}$ \\
\hline & Duration of splinting unknown \\
\hline Outcomes & $\begin{array}{l}\text { Failure of replantation (X-ray revealed a poor healing of the periodontal tissue and root absorp- } \\
\text { tion). Poor masticatory function, degree of tooth movement: II-III, percussion (+) }\end{array}$ \\
\hline Notes & $\begin{array}{l}\text { Kindly translated by Cochrane translating team (Chunjie Li). Further email contact was undertak- } \\
\text { en to clarify the full nature of the intervention (e.g. how was root canal treatment undertaken ex- } \\
\text { tra-orally, how was root canal treatment completed, were antibiotics used, was mouthwash used, } \\
\text { how was pulp disease identified, duration of splinting, was splinting } 3 \text { healthy teeth in total or } 3 \\
\text { healthy teeth per side, further clarification related to outcome), and to explore questions related to } \\
\text { risk of bias. No reply received from the study authors, emails sent in } 2013\end{array}$ \\
\hline
\end{tabular}

$\mathrm{RCT}=$ randomised controlled trial.

Characteristics of ongoing studies [ordered by study ID]

\section{ChiCTR-ICR-15007129}

Trial name or title Effect of platelet-rich fibrin on the periodontal healing of avulsed tooth reimplantation: a randomised controlled trial

Methods

This interventional study aims to compare the periodontal healing of avulsed tooth after being reimplanted alone or combined with autologous platelet-rich fibrin by clinical index of tooth mobility and radiographic index of root resorption using X-ray and cone beam computed tomography (CBCT). Observational period is 2 years

Participants

Inclusion criteria: over 12 years (tooth with closed apex), both male and female, the position of the avulsed tooth involves maxillary and mandibular incisors, the tooth has been out of the alveolar socket over 1 hour, avulsed tooth was kept in dry or inappropriate conditions so that the periodontal ligament tissues have necrosis widely, without root fracture, the patient volunteered for this study and signed the consent

\begin{tabular}{ll}
\hline Interventions & Replanted alone or in combination with autologous platelet-rich fibrin \\
\hline Outcomes & $\begin{array}{l}\text { Periodontal healing, pain, tooth mobility, tooth colour, gingival index, bleeding on probing, fistula, } \\
\text { pulp vitality }\end{array}$ \\
\hline Starting date & 1 December 2014 \\
\hline
\end{tabular}


ChiCTR-ICR-15007129 (Continued)

Contact information

Zhang Min - chief investigator

\section{DATA AND ANALYSES}

\section{Comparison 1. Hyperbaric oxygen versus control}

\begin{tabular}{lllll}
\hline Outcome or subgroup title & $\begin{array}{l}\text { No. of } \\
\text { studies }\end{array}$ & $\begin{array}{l}\text { No. of } \\
\text { partici- } \\
\text { pants }\end{array}$ & Statistical method & Effect size \\
\hline 1 Periodontal healing at 12 months & 1 & 138 & Risk Ratio (M-H, Fixed, 95\% Cl) & $2.04[1.52,2.73]$ \\
\hline 2 Tooth survival at 12 months & 1 & 138 & Risk Ratio (M-H, Fixed, 95\% Cl) & $1.21[1.07,1.36]$ \\
\hline 3 Pulpal healing at 12 months & 1 & 138 & Risk Ratio (M-H, Fixed, $95 \% \mathrm{Cl})$ & $1.25[1.06,1.48]$ \\
\hline
\end{tabular}

Analysis 1.1. Comparison 1 Hyperbaric oxygen versus control, Outcome 1 Periodontal healing at 12 months.

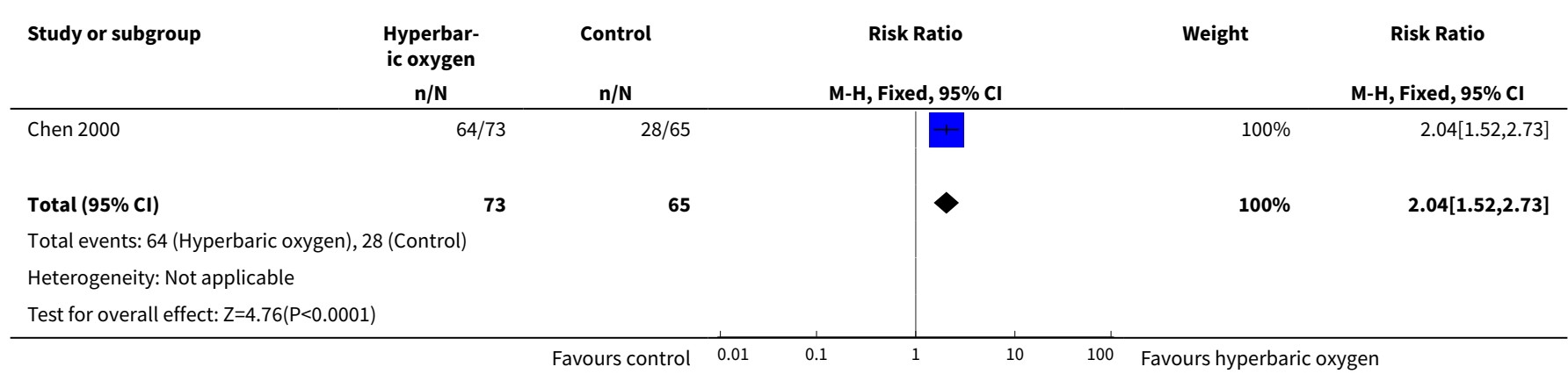

Analysis 1.2. Comparison 1 Hyperbaric oxygen versus control, Outcome 2 Tooth survival at 12 months.

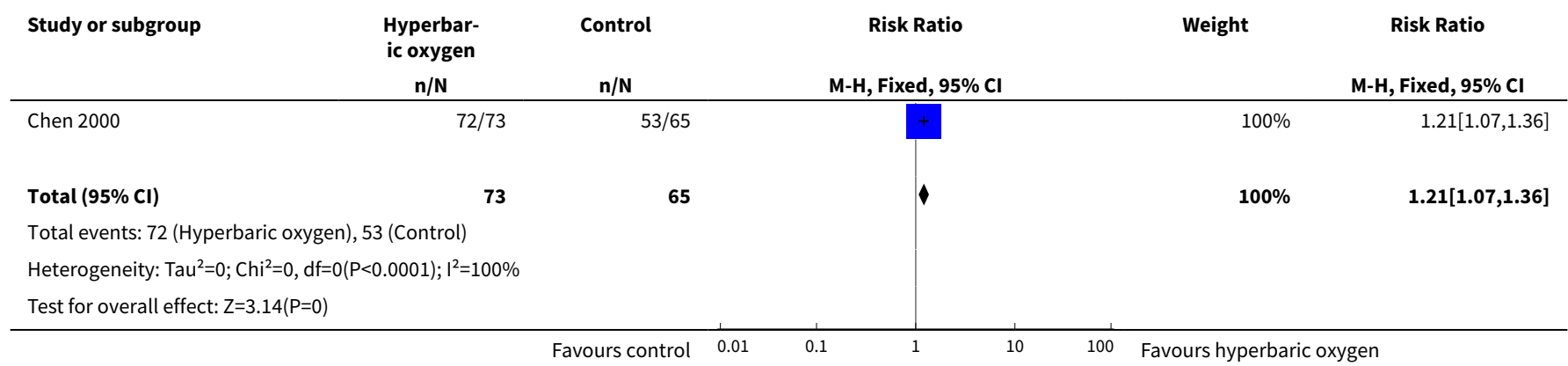


Analysis 1.3. Comparison 1 Hyperbaric oxygen versus control, Outcome 3 Pulpal healing at 12 months.

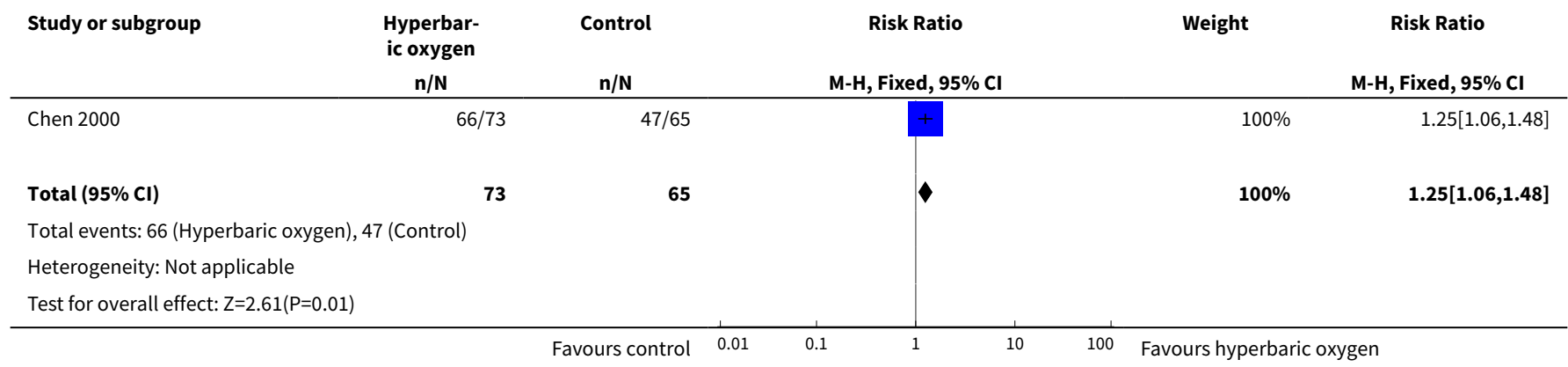

\section{Comparison 2. Ledermix day 0-10 versus Ultracal day 7-10}

\begin{tabular}{llllll}
\hline Outcome or subgroup title & $\begin{array}{l}\text { No. of } \\
\text { studies }\end{array}$ & $\begin{array}{l}\text { No. of } \\
\text { partici- } \\
\text { pants }\end{array}$ & Statistical method & Effect size \\
\hline 1 Peridontal healing at 12 months & 1 & 27 & Risk Ratio (M-H, Fixed, 95\% Cl) & 1.67 [0.80, 3.49] \\
\hline 2 Tooth survival at 12 months & 1 & 27 & Risk Ratio (M-H, Fixed, 95\% Cl) & $0.0[0.0,0.0]$ \\
\hline $\begin{array}{l}\text { 3 Discolouration (patient-reported) at 12 } \\
\text { months - best case scenario for Ledermix }\end{array}$ & 1 & 22 & Risk Ratio (M-H, Fixed, 95\% Cl) & $7.20[1.03,50.28]$ \\
\hline $\begin{array}{l}\text { 4 Discolouration (patient-reported) at 12 } \\
\text { months - worst case scenario for Ledermix }\end{array}$ & 1 & 22 & Risk Ratio (M-H, Fixed, 95\% Cl) & $8.4[1.23,57.29]$ \\
\hline
\end{tabular}

Analysis 2.1. Comparison 2 Ledermix day 0-10 versus Ultracal day 7-10, Outcome 1 Peridontal healing at 12 months.

\begin{tabular}{|c|c|c|c|c|c|}
\hline Study or subgroup & $\begin{array}{c}\text { Ledermix } \\
\mathrm{n} / \mathrm{N}\end{array}$ & $\begin{array}{c}\text { Ultracal } \\
\text { n/N }\end{array}$ & $\begin{array}{c}\text { Risk Ratio } \\
\text { M-H, Fixed, 95\% Cl }\end{array}$ & Weight & $\begin{array}{c}\text { Risk Ratio } \\
\text { M-H, Fixed, 95\% Cl }\end{array}$ \\
\hline Day 2012 & $8 / 12$ & $6 / 15$ & & $100 \%$ & $1.67[0.8,3.49]$ \\
\hline Total $(95 \% \mathrm{CI})$ & 12 & 15 & & $100 \%$ & $1.67[0.8,3.49]$ \\
\hline \multicolumn{6}{|c|}{ Total events: 8 (Ledermix), 6 (Ultracal) } \\
\hline \multicolumn{6}{|c|}{ Heterogeneity: Not applicable } \\
\hline Test for overall effect & & & & & \\
\hline
\end{tabular}

Analysis 2.2. Comparison 2 Ledermix day 0-10 versus Ultracal day 7-10, Outcome 2 Tooth survival at 12 months.

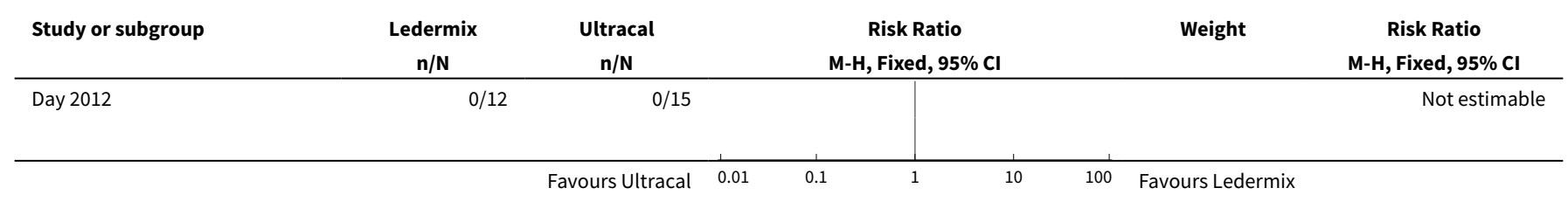




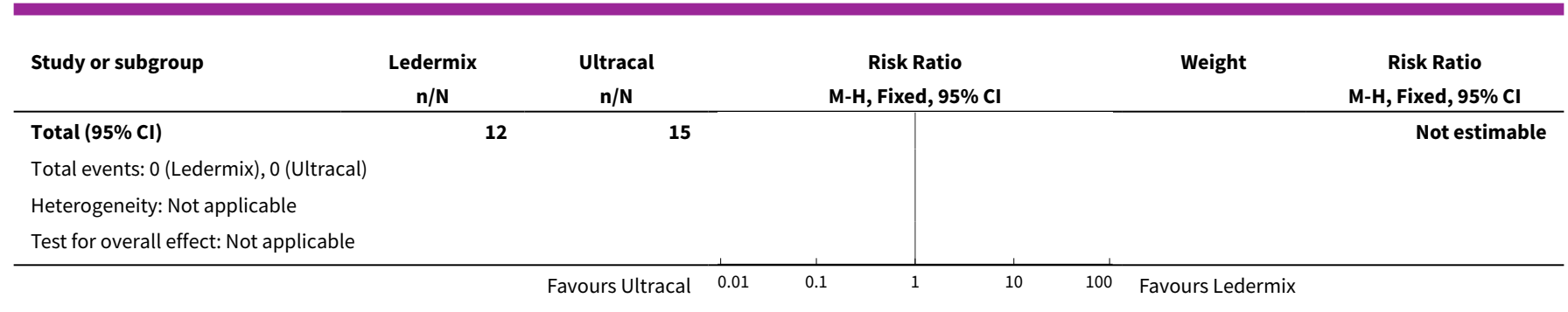

Analysis 2.3. Comparison 2 Ledermix day $0-10$ versus Ultracal day 7-10, Outcome 3 Discolouration (patient-reported) at 12 months - best case scenario for Ledermix.

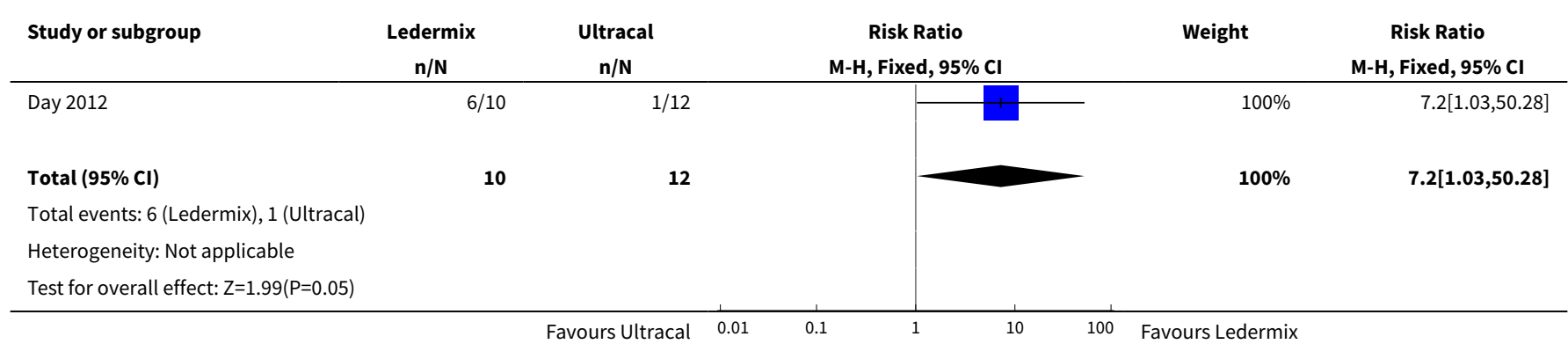

Analysis 2.4. Comparison 2 Ledermix day 0-10 versus Ultracal day 7-10, Outcome 4 Discolouration (patient-reported) at 12 months - worst case scenario for Ledermix.

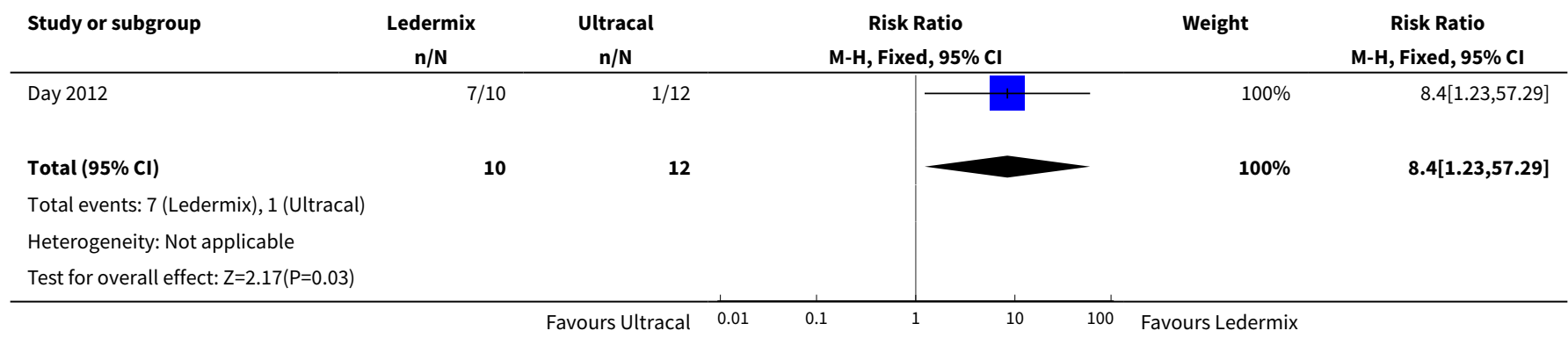

Comparison 3. Pulp extirpation at day 0 (extra-oral) versus day 7 (intra-oral)

\begin{tabular}{llllll}
\hline Outcome or subgroup title & $\begin{array}{l}\text { No. of } \\
\text { studies }\end{array}$ & $\begin{array}{l}\text { No. of par- } \\
\text { ticipants }\end{array}$ & Statistical method & Effect size \\
\hline 1 Radiographic resorption at 12 months & 1 & 19 & Risk Ratio (M-H, Fixed, 95\% Cl) & $1.35[0.81,2.24]$ \\
\hline
\end{tabular}


Analysis 3.1. Comparison 3 Pulp extirpation at day 0 (extra-oral) versus day 7 (intra-oral), Outcome 1 Radiographic resorption at 12 months.

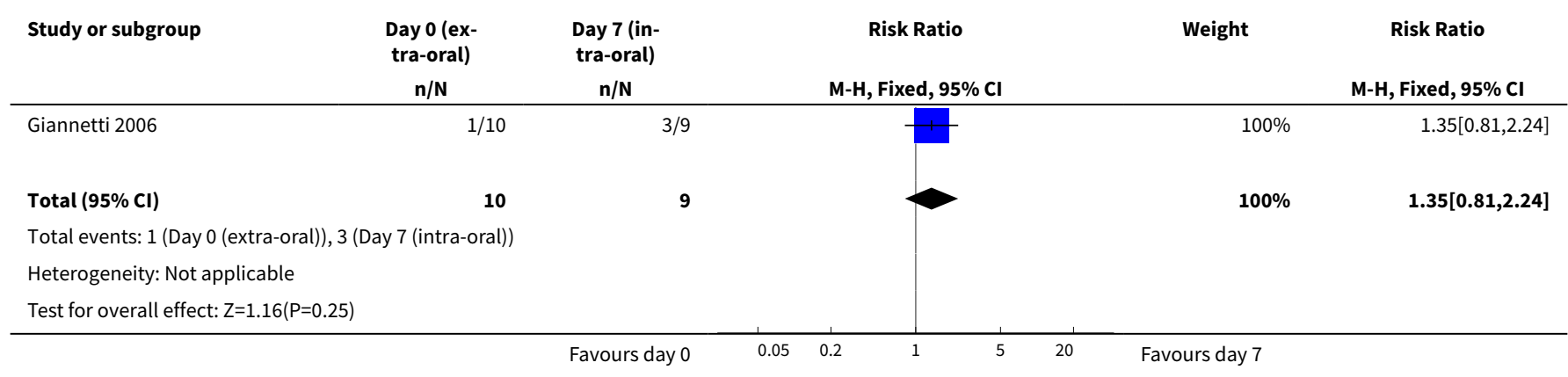

Comparison 4. Thymosin alpha 1 versus saline soaking prior to replantation

\begin{tabular}{lllll}
\hline Outcome or subgroup title & $\begin{array}{l}\text { No. of } \\
\text { studies }\end{array}$ & $\begin{array}{l}\text { No. of } \\
\text { partici- } \\
\text { pants }\end{array}$ & Statistical method & Effect size \\
\hline $\begin{array}{l}1 \text { Periodontal healing at } 48 \\
\text { months }\end{array}$ & 1 & 73 & Risk Ratio (M-H, Random, 95\% Cl) & $5.60[2.22,14.11]$ \\
\hline 2 Tooth survival at 12 months & 1 & 73 & Risk Ratio (M-H, Fixed, 95\% Cl) & $1.46[1.11,1.91]$ \\
\hline 3 Tooth survival at 48 months & 1 & 73 & Risk Ratio (M-H, Fixed, 95\% Cl) & $3.58[1.86,6.89]$ \\
\hline
\end{tabular}

Analysis 4.1. Comparison 4 Thymosin alpha 1 versus saline soaking prior to replantation, Outcome 1 Periodontal healing at 48 months.

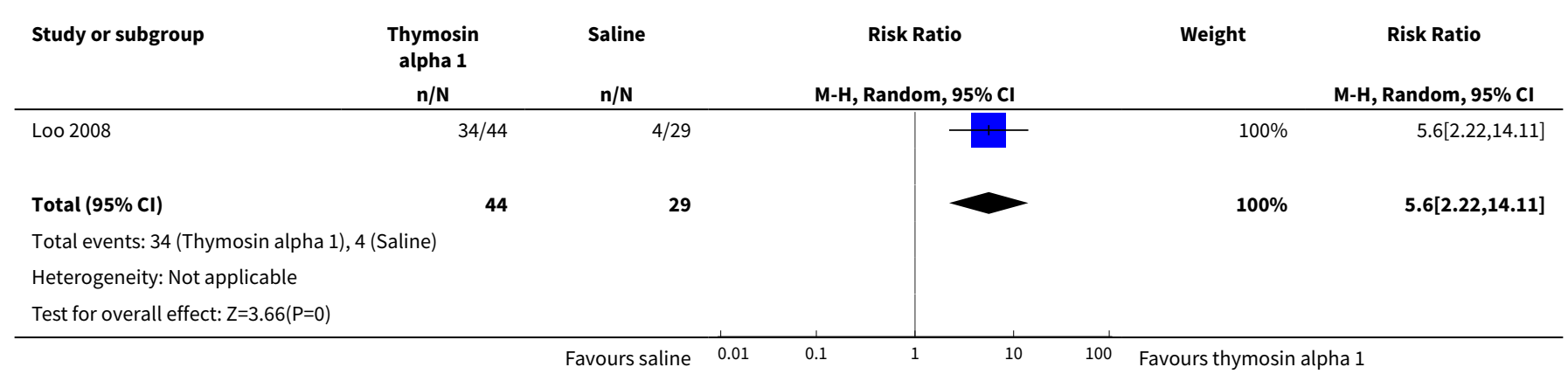

Analysis 4.2. Comparison 4 Thymosin alpha 1 versus saline soaking prior to replantation, Outcome 2 Tooth survival at 12 months.

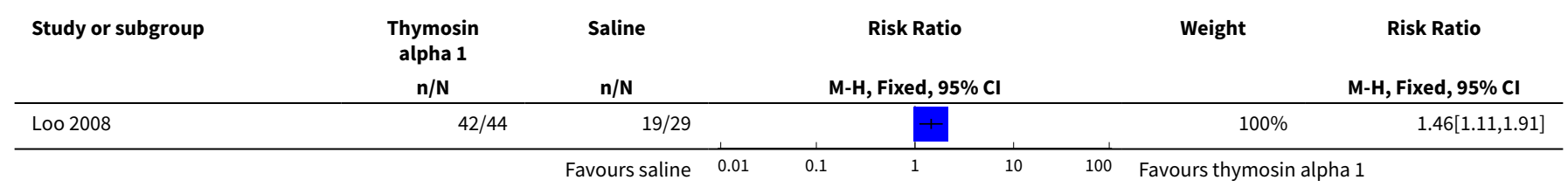




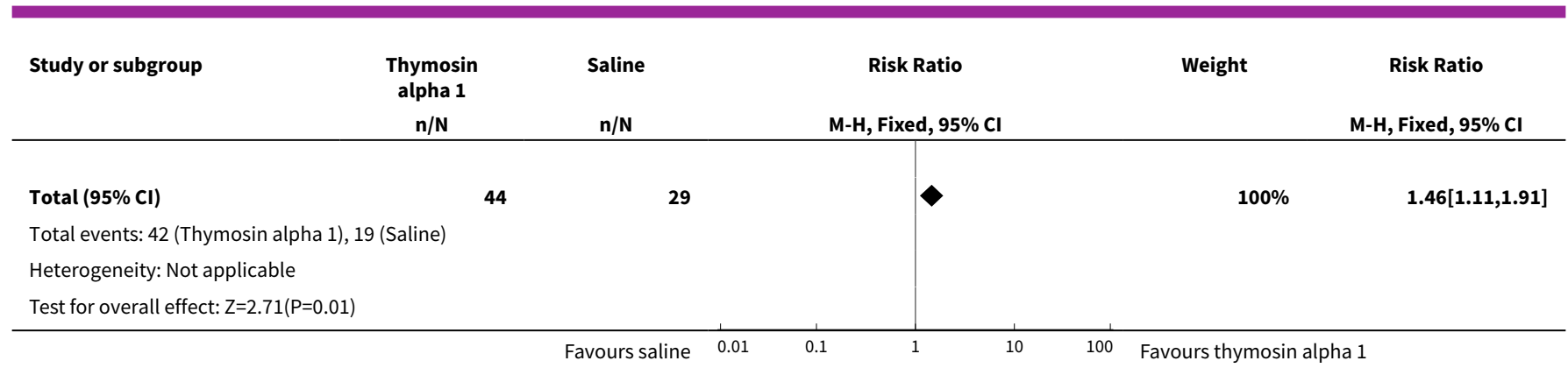

Analysis 4.3. Comparison 4 Thymosin alpha 1 versus saline soaking prior to replantation, Outcome 3 Tooth survival at 48 months.

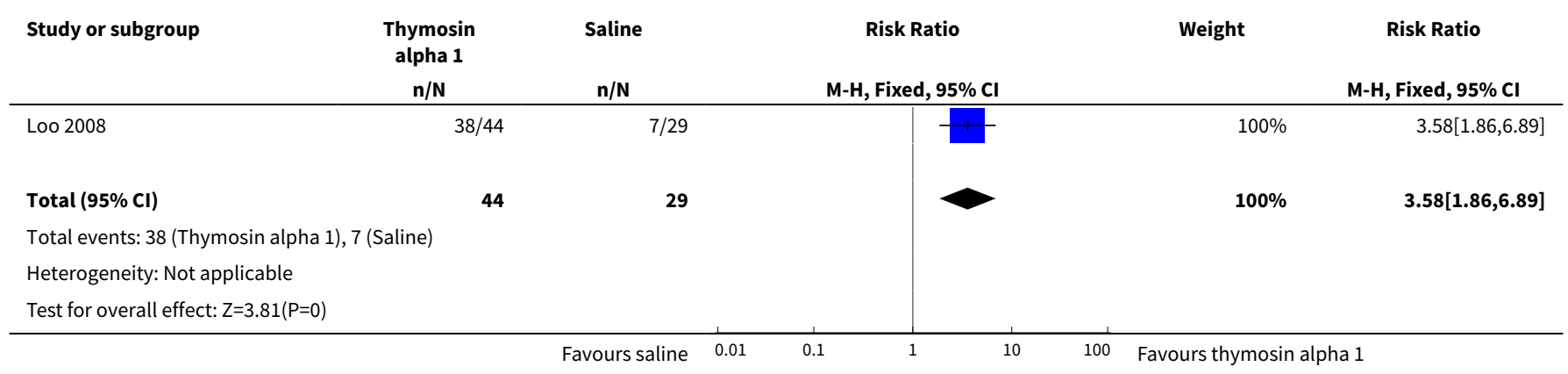

\section{APPENDICES}

\section{Appendix 1. Cochrane Oral Health's Trials Register search strategy}

1 MESH DESCRIPTOR Tooth Avulsion AND INREGISTER

2 ((avuls* near6 tooth) or (avuls* near6 teeth) or (avuls* near6 incisor $\left.\left.{ }^{\star}\right)\right)$ AND INREGISTER

3 ((tooth near6 dislodg*) or (teeth near6 dislodg $\left.{ }^{\star}\right)$ or (dislodge ${ }^{\star}$ near6 incisor $\left.\left.{ }^{\star}\right)\right)$ AND INREGISTER

4 ((tooth near6 "knocked out") or (teeth near6 "knocked out") or (incisor* near6 "knocked out")) AND INREGISTER

5 ((tooth near6 sublux*) or (teeth near6 sublux ${ }^{*}$ ) or (incisor* near6 sublux $\left.{ }^{*}\right)$ ) AND INREGISTER

6 ((tooth near6 replant*) or (teeth near6 replant* ${ }^{\star}$ ) or (incisor near6 replant*)) AND INREGISTER

7 MESH DESCRIPTOR Tooth Replantation AND INREGISTER

8 ((tooth near6 reimplant ${ }^{\star}$ ) or (teeth near6 reimplant $\left.{ }^{\star}\right)$ or (incisor near6 reimplant $\left.\left.{ }^{\star}\right)\right)$ AND INREGISTER

$9 \# 1$ or \#2 or \#3 or \#4 or \#5 or \#6 or \#7 or \#8v

\section{Appendix 2. Cochrane Central Register of Controlled Trials (CENTRAL) search strategy}

\#1 TOOTH AVULSION (single term MeSH)

\#2 ((avuls* near/6 tooth) or (avuls* near/6 teeth) or (avuls* near/6 incisor $\left.\left.{ }^{*}\right)\right)$

\#3 ((tooth near/6 dislodg*) or (teeth near /6 dislodg*) or (dislodge ${ }^{\star}$ near/6 incisor $\left.\left.{ }^{\star}\right)\right)$

\#4 ((tooth near/6 "knocked out") or (teeth near/6 "knocked out") or (incisor* near/6 "knocked out"))

\#5 ((tooth near/6 sublux $\left.{ }^{\star}\right)$ or (teeth near/6 sublux ${ }^{*}$ ) or $\left(\right.$ incisor ${ }^{*}$ near/ 6 sublux $\left.x^{\star}\right)$ )

\#6 ((tooth near/6 replant ${ }^{\star}$ ) or (teeth near/6 replant $\left.{ }^{\star}\right)$ or (incisor near/6 replant $\left.{ }^{\star}\right)$ )

\#7 TOOTH REPLANTATION (Single term MeSH)

\#8 ((tooth near/6 reimplant ${ }^{\star}$ ) or (teeth near/6 reimplant ${ }^{\star}$ ) or (incisor near $/ 6$ reimplant $\left.{ }^{\star}\right)$ )

$\# 9$ \#1 or \#2 or \#3 or \#4 or \#5 or \#6 or \#7 or \#8

\section{Appendix 3. MEDLINE Ovid search strategy}

1. Tooth Avulsion/

2. (avuls\$ adj6 (tooth or teeth or incisor\$)).mp.

3. (dislodg\$ adj6 (tooth or teeth incisor\$)).mp.

Interventions for treating traumatised permanent front teeth: avulsed (knocked out) and replanted (Review) 
4. ((tooth or teeth or incisor\$) adj6 "knocked out").mp.

5. ((tooth or teeth or incisor\$) adj6 sublux\$).mp.

6. ((tooth or teeth or incisor\$) adj6 replant\$).mp.

7. ((tooth or teeth or incisor\$) adj6 reimplant\$).mp.

8. Tooth Replantation/

9. or/1-8

This subject search was linked to the Cochrane Highly Sensitive Search Strategy (CHSSS) for identifying randomised trials (RCTs) in MEDLINE: sensitivity-maximising version (2008 revision) as referenced in Chapter 6.4.11.1 and detailed in box 6.4.c of theCochrane Handbook for Systematic Reviews of Interventions, Version 5.1.0 (updated March 2011) (Lefebvre 2011).

1. randomized controlled trial.pt.

2. controlled clinical trial.pt.

3. randomized.ab.

4. placebo.ab.

5. drug therapy.fs.

6. randomly.ab.

7. trial.ab.

8. groups.ab.

9. or $/ 1-8$

10. exp animals/ not humans.sh.

11.9 not 10

\section{Appendix 4. Embase Ovid search strategy}

1. (avuls\$ adj6 (tooth or teeth or incisor\$)).mp.

2. (dislodg\$ adj6 (tooth or teeth incisor\$)).mp.

3. ((tooth or teeth or incisor\$) adj6 "knocked out").mp.

4. ((tooth or teeth or incisor\$) adj6 sublux\$).mp.

5. ((tooth or teeth or incisor\$) adj6 replant\$).mp.

6. ((tooth or teeth or incisor\$) adj6 reimplant\$).mp.

7. or/1-6

This subject search was linked to an adapted version of the Cochrane Centralised Search Project filter for identifying RCTs in Embase Ovid (see www.cochranelibrary.com/help/central-creation-details.html for information).

1. Randomized controlled trial/

2. Controlled clinical study/

3. Random\$.ti,ab.

4. randomization/

5. intermethod comparison/

6. placebo.ti,ab.

7. (compare or compared or comparison).ti.

8. ((evaluated or evaluate or evaluating or assessed or assess) and (compare or compared or comparing or comparison)).ab.

9. (open adj label).ti,ab.

10. ((double or single or doubly or singly) adj (blind or blinded or blindly)).ti,ab.

11. double blind procedure/

12. parallel group $\$ 1 . t i, a b$.

13. (crossover or cross over).ti,ab.

14. ((assign\$ or match or matched or allocation) adj5 (alternate or group\$1 or intervention\$1 or patient $\$ 1$ or subject $\$ 1$ or participant

\$1)).ti,ab.

15. (assigned or allocated).ti,ab.

16. (controlled adj7 (study or design or trial)).ti,ab.

17. (volunteer or volunteers).ti,ab.

18. trial.ti.

19. or/1-18

20. (exp animal/ or animal.hw. or nonhuman/) not (exp human/ or human cell/ or (human or humans).ti.)

21. 19 not 20

\section{Appendix 5. US National Institutes of Health Ongoing Trials Register (ClinicalTrials.gov) search strategy}

teeth and avulsed

teeth and reimplant

teeth and replant

Interventions for treating traumatised permanent front teeth: avulsed (knocked out) and replanted (Review) 


\section{Appendix 6. World Health Organization International Clinical Trials Registry Platform search strategy}

teeth and avulsed or tooth and avulsed or teeth and avulsion or teeth and avulsion

WHAT'S NEW

\begin{tabular}{lll}
\hline Date & Event & Description \\
\hline 10 June 2018 & $\begin{array}{l}\text { New citation required but conclusions } \\
\text { have not changed }\end{array}$ & $\begin{array}{l}\text { New review author. The review has been extensively rewritten } \\
\text { following expert advice from Cochrane Oral Health. For the in- } \\
\text { cluded studies, some of the original assessments including risk } \\
\text { of bias have changed. 'Summary of findings' tables included }\end{array}$ \\
\hline
\end{tabular}

8 March $2018 \quad$ New search has been performed

Search updated to 8 March 2018. One new study identified and added to the review bringing the total to four included studies. Review updated and revised to ensure it is consistent with current Cochrane methodology and reporting

\section{CONTRIBUTIONS OF AUTHORS}

Peter Day (PD) wrote the protocol. PD co-ordinated the review. PD wrote to study authors for additional information. PD and Monty Duggal (MD) independently and in duplicate assessed the eligibility and quality of trials. PD and MD extracted data from included studies. PD wrote the review and MD edited it for publication. Hani Nazzal (HN) updated the review under the guidance of PD. HN and one of the Cochrane Oral Health editorial team (Philip Riley) independently assessed the new randomised controlled trial published by Day et al (Day 2012). PD and $\mathrm{HN}$ wrote the updated version under the guidance of MD.

\section{DECLARATIONS OF INTEREST}

Peter Day and Monty Duggal were authors of Day 2012. They were not involved in the data extraction or risk of bias assessment of this trial. Hani Nazzal: none known.

\section{SOURCES OF SUPPORT}

\section{Internal sources}

- Leeds Dental Institute, University of Leeds, UK.

\section{External sources}

- National Institute for Health Research (NIHR), UK.

This project was supported by the NIHR, via Cochrane Infrastructure funding to Cochrane Oral Health. The views and opinions expressed herein are those of the review authors and do not necessarily reflect those of the Systematic Reviews Programme, the NIHR, the NHS or the Department of Health.

- Cochrane Oral Health Global Alliance, Other.

The production of Cochrane Oral Health reviews has been supported financially by our Global Alliance since 2011 (oralhealth.cochrane.org/partnerships-alliances). Contributors over the past year have been the American Association of Public Health Dentistry, USA; AS-Akademie, Germany; the British Association for the Study of Community Dentistry, UK; the British Society of Paediatric Dentistry, UK; the Canadian Dental Hygienists Association, Canada; the Centre for Dental Education and Research at All India Institute of Medical Sciences, India; the National Center for Dental Hygiene Research \& Practice, USA; New York University College of Dentistry, USA; NHS Education for Scotland, UK; and the Swiss Society for Endodontology, Switzerland.

\section{DIFFERENCES BETWEEN PROTOCOL ANDREVIEW}

The protocol and review differ slightly in the methodology section as a result of slight changes in guidance from Cochrane with regards to the assessment and presentation of the risk of bias in included studies.

Moreover since the publication of the first review in 2010, we have moved some of the primary outcomes (tooth survival, pulpal healing, and pain) to secondary outcomes. In addition, we have included new secondary outcomes as outlined by the internationally agreed core outcome set for dental traumatology (Kenny 2018). These include: oral health-related quality of life, aesthetics (discolouration), trauma- 
related dental anxiety, infraocclusion, and other complications or side effects. This updated version of the review now also includes 'Summary of findings' tables and both randomised and quasi-randomised controlled trials.

\section{NDEX TERMS}

\section{Medical Subject Headings (MeSH)}

Bone Development [physiology]; Calcium Hydroxide [therapeutic use]; Demeclocycline [therapeutic use]; Drug Combinations; Hyperbaric Oxygenation; Incisor [ ${ }^{*}$ injuries]; Periodontal Ligament [growth \& development]; Preoperative Care [methods]; Randomized Controlled Trials as Topic; Root Canal Irrigants [therapeutic use]; Tooth Avulsion [ ${ }^{\star}$ surgery]; Tooth Discoloration [chemically induced]; Tooth Replantation [ ${ }^{*}$ methods]; Triamcinolone Acetonide [therapeutic use]

\section{MeSH check words}

Humans 